Advanced Technology Laboratories

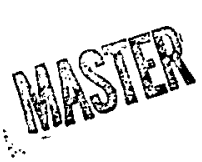

A Division of American-Standard

\title{
INVESTIGATION OF
}

THERMA L-STRESS-FATIGUE BEHAVIOR

OF STAIN LESS STEELS

\author{
Prepared under \\ AEC Contract AT(04-3)-25.0 \\ Project Agreement No. 11 \\ for the
}

Joint U.S. -Euratom Research and Development Board

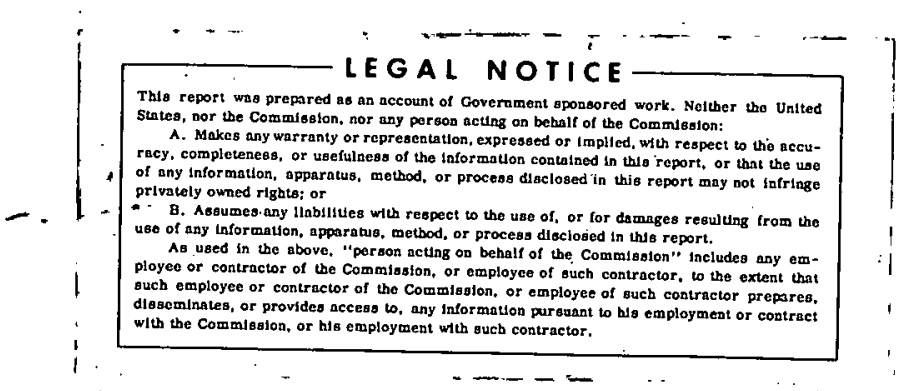

Mountain View, California

Facsimile Price $\$ 3.60$

Microfilm Price \$

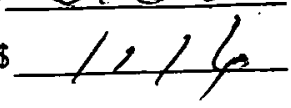

Avoilable from the

Office of Technical Services

Department of Commerce

Woshington 25, D. C. 


\section{DISCLAIMER}

This report was prepared as an account of work sponsored by an agency of the United States Government. Neither the United States Government nor any agency Thereof, nor any of their employees, makes any warranty, express or implied, or assumes any legal liability or responsibility for the accuracy, completeness, or usefulness of any information, apparatus, product, or process disclosed, or represents that its use would not infringe privately owned rights. Reference herein to any specific commercial product, process, or service by trade name, trademark, manufacturer, or otherwise does not necessarily constitute or imply its endorsement, recommendation, or favoring by the United States Government or any agency thereof. The views and opinions of authors expressed herein do not necessarily state or reflect those of the United States Government or any agency thereof. 


\section{DISCLAIMER}

Portions of this document may be illegible in electronic image products. Images are produced from the best available original document. 


\section{LEGAL NO'TICE}

T)

spons

nor an

A

implie

useful

that th

disclo

or

B

or for

appar

A.

\section{LEGAL NOTICE}

This document was prepared under the sponsorship of the United States Atomic Energy Commission pursuant to the Joint Research and Development Program established by the Agreement for Cooperation signed November 8, 1958 between the Government of the United States of America and the European Atomic En- Or ergy Community (Euratom). Neither the United States, the U. S. Atomic Energy Commision, the European Atomic Energy Community, the Euratom CommisBion, nor any person acting on behalf of either Commission:

A. Makes any warranty or representation, express or implied, with respect to the accuracy, completeness, or usefulness of the information contained in this document, or that the use of any information, apparatus, method, or process disclosed in this document may not infringe privately owned rights; or

B. Assumes any liabilities with respect to the use of, or for damages resulting from the use of any information, apparatus, method or process disclosed in this document.

As used in the above, "person acting on behalf of either Commission" includes any employee or contractor of either Commission or employee of euch contractor to the extent that such employee or contractor or employee of such contractor prepares, handles, disseminates, or provides access to, any infor -

Comm employment with ouch contractor. or em

or con

prepai

pursu:

his employment with such contractor.

mmission,

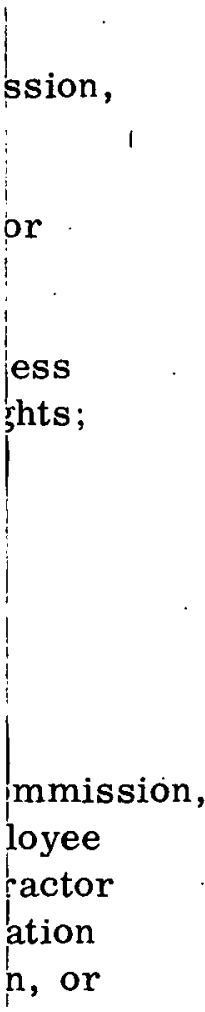


EURAEC-

A TL-A-140

Joint U.S. - Euratom Research

and Development Report

Special Distribution

INVESTIGATION OF

\section{THERMAL-STRESS-FATIGUE BEHAVIOR}

OF STAINLESS STEELS

Quarterly Progress Report No. 8

ATL Job 121200

October-December 1963

Submitted by:

Approved by:
K. E. Horton

D. D. Foley

R. S. Stewart

Advanced Technology Laboratories

A Division of American-Standard

369 Whisman Road

Mountain View, California

Prepared under

AEC Contract AT(04-3)-250

Prọject Agreement No. 11

for the

Joint U.S. - Euratom Research and Development Board 


\section{INTRODUCTION}

The United States and the European Atomic Energy Community (Euratom), on May 29, and June 18, 1958, signed an agreement which provides a basis for cooperation in programs for the advancement of the peaceful applications of atomic energy. This agreement, in part, provides for the establishment of the Joint U.S. -Euratom research and development program which is aimed at reactors to be constructed in Europe under the Joint Program.

The work described in this report represents the Joint U.S. -Euratom effort which is in keeping with the spirit of cooperation in contributing to the common good by the sharing of scientific and technical information and minimizing the duplication of effort by the limited pool of technical talent available in western Europe and the United States. 


\section{SUMMARY}

Phase I of the program on thermal-stress-fatigue (TSF) testing of 304 and 304-L austenitic stainless steels has been completed. The topical report covering this phase has nearly been completed.

The testing of ferritic steel (ASTM Type A302, Grade B) and of martensitic stainless steel (Type 403) has been approximately 50\% completed, with full completion on A302B contemplated for the next quarter.

During this quarter, TSF and conventional strain-cycling fatigue (SCF) were performed on A302B and 403 steels. A new graphical technique was developed which simplifies the work required to obtain plastic strain range, the variable found to be entirely independent in TSF. The new method also allows greater accuracy in obtaining this parameter. 


\section{PRINCIPAL INVESTIGATORS}

Investigators on the project include K. E. Horton, Project Leader, and R. S. Stewart, Section Supervisor.

\section{STATEMENT ÖF PROBLEM}

The thermal-stress-fatigue behavior of reactor materials, in particular stainless steels, cannot be predicted by extrapolation of known data such as conventional fatigue data. Because thermal fatigue may be a major consideration in reactor core and vessel design, suitable engineering data are needed. The objective of this program is to obtain thermal-stress-fatigue data on various types of stainless steels for the conditions that may be encountered in reactor operation and if possible to separate the effects of the various environmental and metallurgical variables. The isolation of variables should allow a theoretical treatment of data that would eventually lead to the formalization of generalized equations for predicting thermal-stress-fatigue life for any reactor conditions.

\section{PROGRESS OCTOBER-DECEMBER 1963}

\section{A. Type A302B Ferritic Steel}

The testing of this steel was continued during the quarter. The previous difficulty of oxidation during tests performed in argon and vacuum were overcome by the rebuilding of one TSF tester into a high-vacuum setup. The rebuilt chamber is shown in Figure 1 . Although this chamber easily evacuates to $1 \times 10^{-6} \mathrm{~mm} \mathrm{Hg}$, a zirconium gettering filament has also been incorporated to preferentially capture any oxygen that may still be present in the chamber.

The very low strength of $\mathrm{A} 302 \mathrm{~B}$ at elevated temperatures has dictated a maximum temperature of $500^{\circ} \mathrm{C}$ as suitable for TSF testing. As a result, a significant portion of the tests are of the high-cycles-to-failure, low-plastic-strain-range $\left(\Delta \epsilon_{p}\right)$ type.

In the range of $\Delta \epsilon_{\mathrm{p}}$ 's below $1 \times: 10^{-3}$, an appreciable error is graphically introduced in calculating $\Delta \epsilon_{p}$ by the method formerly used. That is, when the constrained measurement gage length $\left(\ell_{0}^{\prime}\right)$ movement (recorded versus time) is graphically subtracted from the unconstrained $\ell_{0}^{\prime}$ movement (recorded versus time), a slight

* See Topical Report, ATL-A-136, 10 May 1962. 
misplacement of the time axis before subtraction can lead to dismaying errors in the calculated value of $\Delta \epsilon_{\mathrm{p}}$.

This method is, of course, theoretically correct for determining $\Delta \epsilon_{\mathrm{p}}$ within $\ell_{0}^{\prime}$ ' even if plastic strain also occurs outside of $\ell_{0}^{\prime}$. The method assumes that $\Delta \epsilon$ is constant within $\ell_{0}^{\prime}$, and for a $\frac{1}{2}$-inch $\ell_{0}^{\prime}$ this assumption is nearly correct. It perhaps should be mentioned that $\Delta \epsilon_{\mathrm{p}}$ was obtained by plotting the remainder of the above subtraction process versus load (both are known as a function of time), and since the width of the resulting hysteresis loop is directly proportional to plastic movement, $\delta_{\mathrm{p}}$, it was necessary only to $\because$. divide $\delta_{\mathrm{p}}$ by $\ell_{\mathrm{o}}{ }^{\prime}$ to obtain $\Delta \epsilon_{\mathrm{p}}$.

An alternative way to obtain $\Delta \epsilon_{\mathrm{p}}$ is to record the following measurements on an $\mathrm{X}-\mathrm{Y}$ recorder: 1) temperature versus unconstrained movement of $\ell_{0}^{\prime}, 2$ ) temperature. versus load, and 3) temperature versus constrained movement of $\ell_{0}$. Such recordings are illustrated in Figure 2. This method differs from that proposed by others ${ }^{*}$ in that the additional step. 3 is included which, since it allows for plastic strain outside the measurement gage length, allows the practically valid assumption of $\Delta \epsilon_{\mathrm{p}}$ being constant within $\ell_{0}{ }^{\prime}$. The advantage of having $\Delta \epsilon_{\mathrm{p}}$ " constant within $\ell_{\mathrm{o}}$ " is clearly seen in equation 3 , which is herederived..

$$
\begin{aligned}
& \delta_{\mathrm{p}}=\delta_{1}+\delta_{2}=\ell_{1} \Delta \epsilon_{\mathrm{p}_{1}}+\mathrm{l}_{2} \Delta \epsilon_{\mathrm{p}_{2}^{\prime}}+\ell_{\mathrm{o}}{ }^{\prime} \Delta \epsilon_{\mathrm{p}_{3}}^{\prime}+\ell_{\mathrm{o}}{ }^{\prime} \Delta \epsilon_{\mathrm{p}_{3}}^{\prime \prime} \\
& { }^{-\ell}{ }_{1} \Delta \mathrm{p}_{1}-\ell_{2} \Delta \epsilon \mathrm{p}_{2} \\
& \delta_{\mathrm{p}}=\ell_{\mathrm{o}}^{\prime}\left(\Delta \epsilon_{\mathrm{p}}^{\prime}+\Delta \epsilon_{\mathrm{p}}^{\prime \prime}\right) \\
& \sum_{i} \Delta \epsilon_{p_{3}}=\frac{\ell_{0}^{\prime \prime}\left(\Delta \epsilon_{p_{3}^{\prime}}^{\prime}+\Delta \epsilon_{p_{3}^{\prime \prime}}^{\prime}\right)}{\ell_{0}^{\prime}}
\end{aligned}
$$

That is, $\delta_{p}$ is divided by a constant length, $\ell_{o}{ }^{\prime}$, which is easily measurable.

An even more direct graphical method than that shown in Figure 2 is available to obtain $\Delta \epsilon_{\mathrm{p}}$. With reference to Figure $\ddot{3}$, it is seeñ thát $\delta_{1}$ would be the value of $\delta_{\mathrm{p}}$ if we neglect

* Prof. A. Carden, University of Alabama, private communication, 1963.

** See list of symbols, page 
the fact that this $\delta$ is obtained by measuring the instantaneous length of $\ell_{0}$ ' at two different temperatures (where $\mathrm{P} \stackrel{!}{=} 0$ ). The addition of $\delta_{2}$ to $\delta_{1}$ corrects for the difference in temperature at zero loads. The value of $\Delta \epsilon_{\mathrm{p}}$ is found by algebraically adding $\delta_{1}$ and $\delta_{2}$ and dividing the sum by $\ell_{0}$ '

It may be argued that if $\Delta \epsilon_{p}$ is not constant within $\ell_{0} !$ (that is, if temperature is not uniform over $\ell_{0}^{\prime}$ ), the two graphical methods just discussed will be in error proportional to the variation in temperature gradient along $\ell_{0}^{\prime}$. With the experimental equipment and specimen design used by; $\mathrm{ATL}$, the maximum variation of $\mathrm{T}$ along $\ell_{0}^{\prime}$ is approximately $20^{\circ} \mathrm{C}$, a value sufficiently small to disallow a significant strength (or ductility) variation along $\ell_{0}$. On the other hand, the variation in $\mathrm{T}$ along the total geometric gage length ${ }^{*}$ can be as great as $400^{\circ} \mathrm{C}$. Clearly, this magnitude will greatly vary strength along the length; it thus becomes necessary to correct for this variation by dividing $\delta_{p}$ measured over the geometric length by a completely fictitious length to get $\Delta \epsilon_{\mathrm{p}}$ maximum. The divisor is fictitious in the sense that total plastic movement of the specimen was measured and this value must be divided by a length to give $\Delta \epsilon_{\mathrm{p}}$ such that had uniform plastic movement been measured over this length and divided by this length the same value of $\Delta \epsilon_{p}$ would result.

The graphical technique illustrated in Figure 3 is very rapid and has been adopted for use on this program in the future. With this method it is easy to ascertain values of $\Delta \epsilon \mathrm{p}$ as small as $5 \times 10^{-5}$, whereas the older method of calculating $\Delta \epsilon$ was limited to values of $\Delta \epsilon_{p}$ in the $5 \times 10^{-4}$ range and above. The difficulty of calculating small values of $\Delta \epsilon_{p}$ by the old method, and the oxidation problem noted earlier, were responsible for the data scatter mentioned in the previous quarterly progress report. ${ }^{\dagger}$ The new ${ }^{\dagger} \dagger$ graph of $\Delta \epsilon_{\mathrm{p}}$ versus $\mathrm{N}$ is shown in Figure 4. There are two noteworthy manifestations on this graph: 1) the agreement between TSF failure and conventional fatigue (straincycling) failure data, and 2) the graphical inference of only one line of one slope for describing both stable and unstable (buckling) failure. This observation suggests

* Length of minimum cross-sectional area.

** The direct readout of movement is possible to $2 \times 10^{-5} \pm 1 \times 10^{-5}$.

$\dagger$ K. E. Horton, "Thermal-Stress-Fatigue Behavior of Stainless Steels, "Quarterly Progress Report No. 7, July-September 1963, ATL-A-139.

$\dagger \dagger$ To replace Figure 9 of Quarterly Progress Report No. 7, ATL-A-139. 
that instability. failure is a metallurgical phenomenon and not a phenomenon dependent on specimen geometry. Whether or not there is any difference in the curves for unstable and stable failures is not certain; however, there is a substantial difference between these two failure curves in. 304-L stainless steel.

In the test program just completed on $304-\mathrm{L}$ stainless, an unsuccessful attempt was made to distinguish between stable and unstable fatigue life at a given level of plastic strain range. Since this attempt was made by varying the specimen wall thickness, it was assumed that the thinner walled specimens were geometrically more unstable. Actually, the test conditions may have been such that the specimens were metallurgically unstable in that. a net plastic strain occurred in one direction (during compression at elevated temperatures). The longitudinal temperature gradient present would transform a cylindrical shape into a barrel shape, which would certainly be conducive to unstable failure as illustrated in Figure 5. Whatever the cause for instability failure, it is uncertain if it is experimentally possible to cause TSF failure in $304-\mathrm{L}$ of any specimen design in the low cycle-to-failure range and not get an instability failure. The same uncertainty exists for A302B ferritic steel.

The structures of the specimens after testing are shown in Figures 7 through 11; Figure 6 is included to allow comparison with the untested structure. In these photomicrographs, it is seen that the low-cycles-to-failure structure (Figure 7) is different from both the as-reversed and the high-cycles-to-failure structures. The structure shown in Figure 7 was obtained by TSF testing between 800 and $200^{\circ} \mathrm{C}$. This same structure can also be obtained by water quenching $\mathrm{A} 302 \mathrm{~B}$ from $927^{\circ} \mathrm{C}$, as shown in Figure 12. This structure is probably upper bainite, although it is very soft due to the low carbon content of A302B.

* K. E. Horton, "Thermal-Stress-Fatigue Behavior of Stainless Steels, "Quarterly Progress Report No. 7, July-September 1963, ATL-A-139, Figure 3.

** To resolve this uncertainty, it is planned to reverse the stress-temperature relationship. That is, specimens will be in tension at the high temperature and in compression at the low temperature. This end will be accomplished with slight modification of existing strain-cycling equipment. 
Of interest is the completely different structure obtained by TSF cycling a specimen identical to that shown in Figure 7 but without a hold time at temperature extremes. This new structure, shown in Figure 13, is probably due to insufficient time for austenitizing; hence little if any bainite is formed.

The significantly different structures present in TSF-tested A302B do not alter the position of the failure curve shown in Figure 4. While this may appear remarkable, it should be remembered that all the structures exhibited by A302B are merely different arrangements of ferrite and cementite.

The oxidation that took place during the air tests and vacuum tests conducted before the rebuilding of the vacuum test chamber prohibits determination of the fracture path. However, the oxide formation in a fatigue crack does serve a useful purpose in that it allows a rough estimate of the fracture rate. To illustrate, Figures 14 and 15 show a uniform gradation in oxide thickness in the fatigue crack, which suggests a uniform rate of crack propagation. Furthermore, comparison of the maximum thickness of the fracture-path oxide with the thickness of the surface oxide indicates that fracture did not start until about two-thirds of fatigue life was reached.

\section{B. Type 403 Martensitic Stainless Steel:}

The failure curve for the data obtained to date on this steel is plotted in Figure 16. When this graph is compared to that in Figure 4, it is seen that Type 403 steel is more fatigue resistant than A302B ferritic steel. Both graphs have similar slopes, however. The structures of 403 steel in various conditions are illustrated in Figures 17, 18, 19, and 20, for "comparison with" TSF-tested structures... It can be seen that the quenching portion of the heat treatment produces a martensitic structure, which, of course, is tempered by reheating to $\sim 650^{\circ} \mathrm{C}$. The structures after fatigue testing are shown in Figures 21 through 24. Figure 21 shows that complete tempering has occurred by cycling from $700^{\circ} \mathrm{C}$ with 1 -minute hold at this temperature. Even without the 1-minute hold at $700^{\circ} \mathrm{C}$ during TSF cycling from $700^{\circ} \mathrm{C}$, tempering is comparable to a 24-hour temper at $645^{\circ} \mathrm{C}$, as seen by comparing Figures 22 and 20. TSF cycling or strain cycling at lower temperatures does not change the tempered martensitic structure originally present except perhaps for a slight further tempering, as shown by comparing Figures 23 and 24 with Figures 19 and 20 . The type of fracture paths is difficult to ascertain due to the finegrain structures present. 
Since many tests remain to be performed on 403 steel, discussion of its TSF characteristics is premature. However, there is one noteworthy early conclusion: TSF and SCF failures are indistinguishable on the plot of $\Delta \epsilon_{\mathrm{p}}$ versus $\mathrm{N}$. On the other hand, there is an appreciable difference between TSF and SCF data points on a plot of stress versus N, as shown in Figure 25. This state of affairs suggests that $\Delta \epsilon_{p}$ is the independent test variable.

\section{PLANS FOR FUTURE WORK}

Testing of A302B ferritic pressure-vessel steel will be completed during the next quarter. Prior to completion of these tests, a few preliminary tests will be performed on Croloy $2 \frac{1}{4}$ steel specimens to determine if the specimen design and fabrication result in satisfactory performance. The Croloy specimens are a composite, welded structure in which failure could occur at the weld regions of unsatisfactory specimens. These early tests on Croloy $2 \frac{1}{4}$ will insure full-scale testing of this material after completion of A302B testing.

A few TSF tests will be run in conjunction with ultrasonic testing for fatigue cracks. These tests will permit determination of rate of fatigue-crack growth and time for crack initiation.

\section{CONCLUSIONS}

1) A significant improvement has been made in the technique for obtaining $\Delta \epsilon_{\mathrm{p}}$. The new method is particularly useful in the high-cycles-to-failure tests, permitting accurate measurement of plastic strains as small as 50 microinches per inch.

2) There is only one fatigue-failure curve on graphs of $\Delta \epsilon_{p}$ versus $N$ for both pure - fatigue and instability failures of A302B ferritic pressure-vessel steel and 403 martensitic stainless steel. This is in direct contrast to the results on 304-L stainless steel and suggests that instability failure is a metallurgical phenomenon that is not geometrically dependent on the specimen design.

3) Failures by SCF and TSF are indistinguishable on graphs of $\Delta \epsilon_{p}$ versus $N$, indicating that $\Delta \epsilon_{\mathrm{p}}$ is the independent variable. 


\section{LIST OF SYMBOLS}

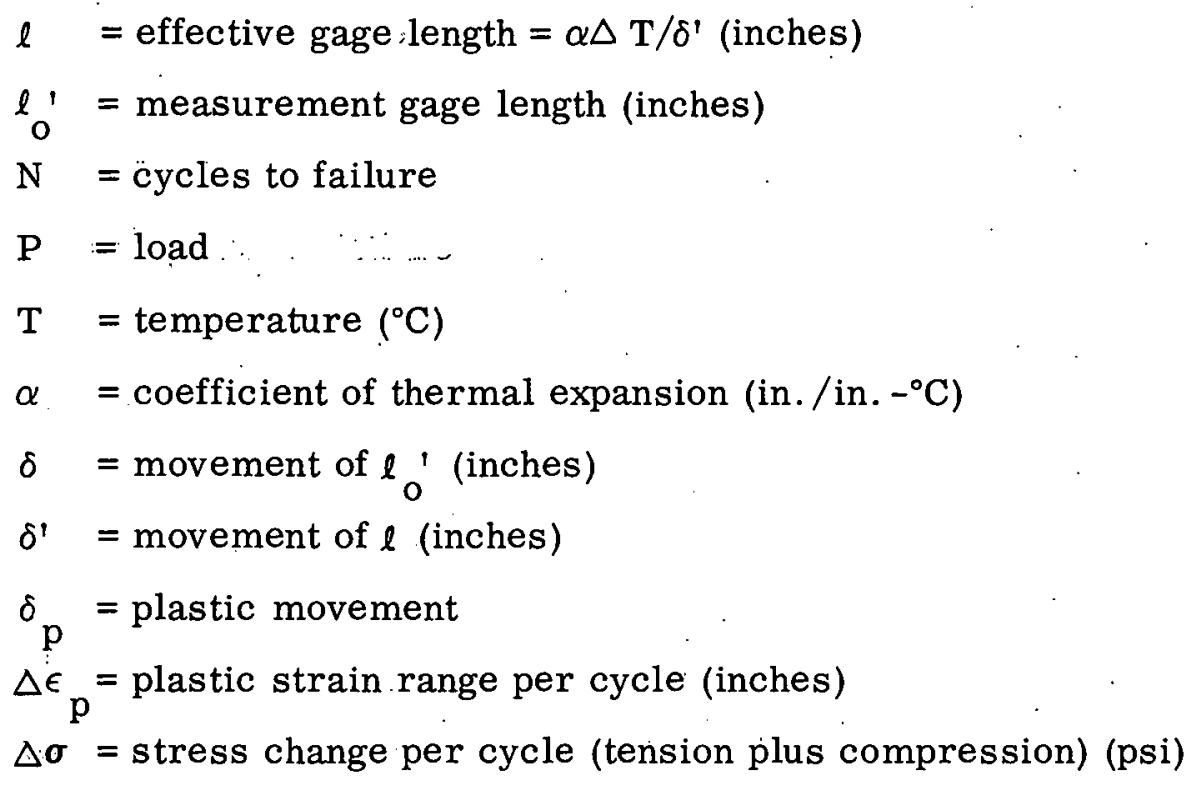




\section{REPORTS ISSUED SINCE INCEPTION OF PROGRAM}

Quarterly Technical Progress Report, January-March 1962, AT L-A-130, EURAEC 336 Quarterly Technical Progress Report, April-June 1962, ATL-A-131, EURAEC 335 Quarterly Technical Progress Report, July-September 1962, ATL-A-133, EURAEC 481 Quarterly Technical Progress Report, October-December 1962, ATL-A-134, EURAEC 555 Quarterly Technical Progress Report, January-March.1963, ATL-A-135, EURAEC 632 Topical Report, 10 May 1962, * ATL-A-136, EURAEC 725

Quarterly Technical Progress Report, April-June 1963, ATL-A-137, EURAEC 756 Quarterly. Technical Progress Report, July-September 1963, ATL-A-139, EURAEC 841

* Report should have been dated 1963. 
TABLE I

PROPOSED TESTING PROGRAM

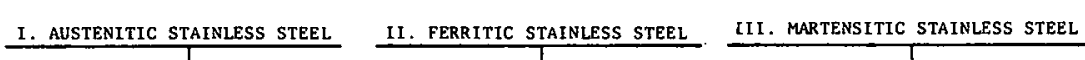

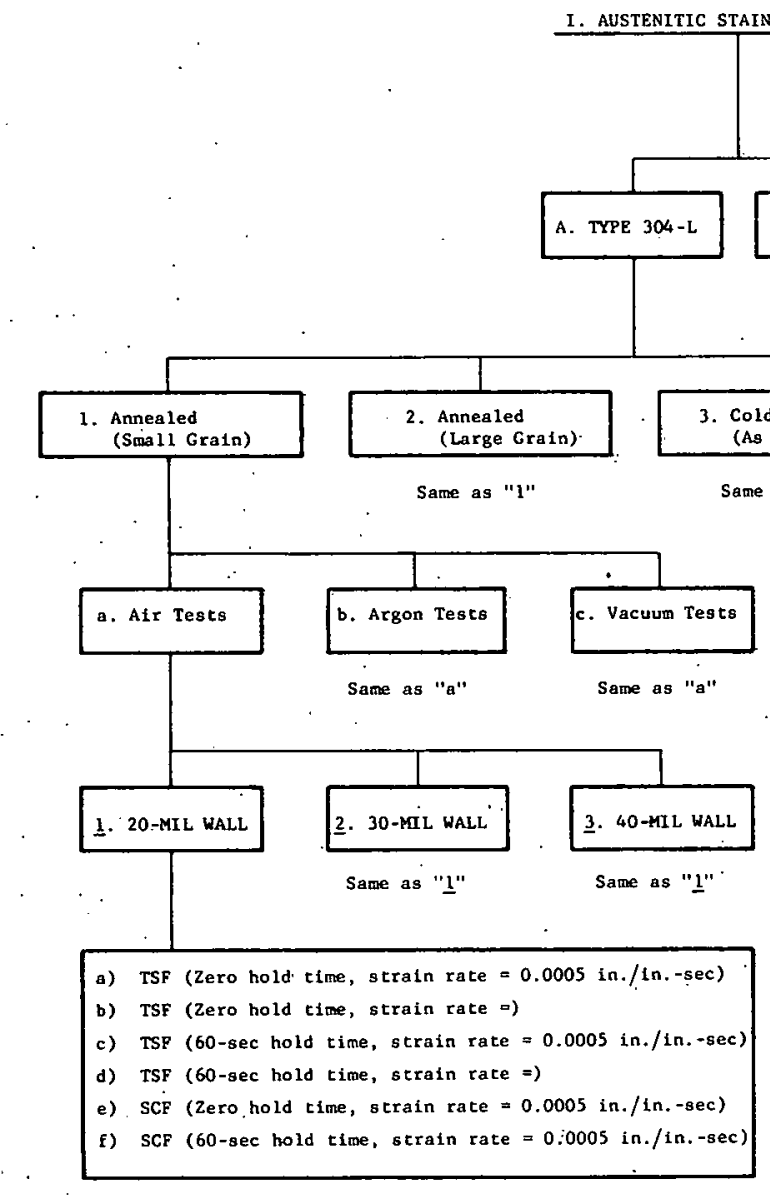

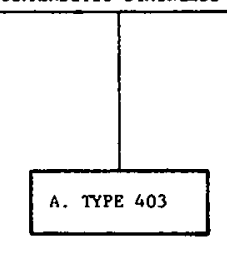

ame as "I"

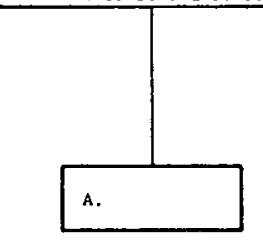

Same as "I"

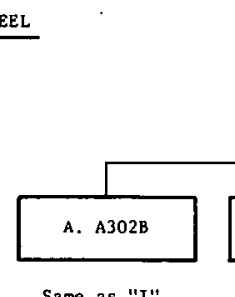

Same as "I"
IV. OTHER FERROUS ALLOYS

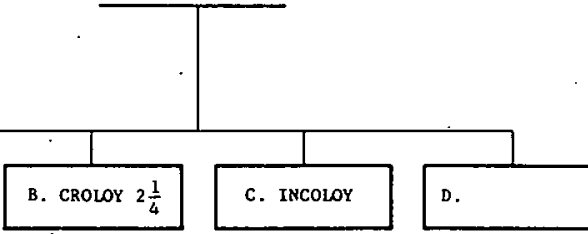

Same as "I"
Same as "I" .

Same as "I"

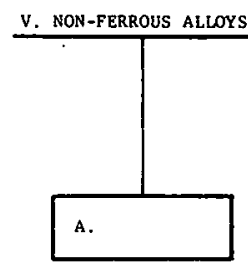

Same as "I" (a-d) TSF

\begin{tabular}{|c|c|c|c|c|}
\hline \multicolumn{5}{|c|}{ HIGH TEMPRRATURE - LOH TEMPERATURE } \\
\hline & 1 & 2 & 3 & 4 \\
\hline $\mathrm{a}$ & $500-300$ & $600-400$ & $700-500$ & $400-200$ \\
\hline$b$ & $550-250$ & $700-300$ & $800-400$ & $450-150$ \\
\hline $\mathrm{c}$ & $600-200$ & $800-200$ & $850-350$ & $500-100$ \\
\hline$d$ & $700-100$ & $900-100$ & $900-300$ & $550-50$ \\
\hline
\end{tabular}

$(e-f) s c e$

\begin{tabular}{|c|c|c|c|c|c|}
\hline & Temperature & \multicolumn{5}{|c|}{ Equivalent Strain Range $\Delta \mathrm{T}$} \\
\cline { 3 - 6 } & of Tests & $\mathrm{L}$ & 2 & 3 & 4 \\
\hline $\mathrm{a}$ & 400 & $\Delta \mathrm{T}=400$ & $\Delta \mathrm{T}=600$ & $\Delta \mathrm{T}=800$ & $\Delta \mathrm{T}=300$ \\
\hline $\mathrm{b}$ & 500 & $"$ & $"$ & $"$ & $"$ \\
\hline $\mathrm{c}$ & 600 & $"$ & $"$ & $"$ & $"$ \\
\hline $\mathrm{d}$ & 200 & & $"$ & $"$ & $"$ \\
\hline
\end{tabular}

See right for delineation of a) through f) above. 


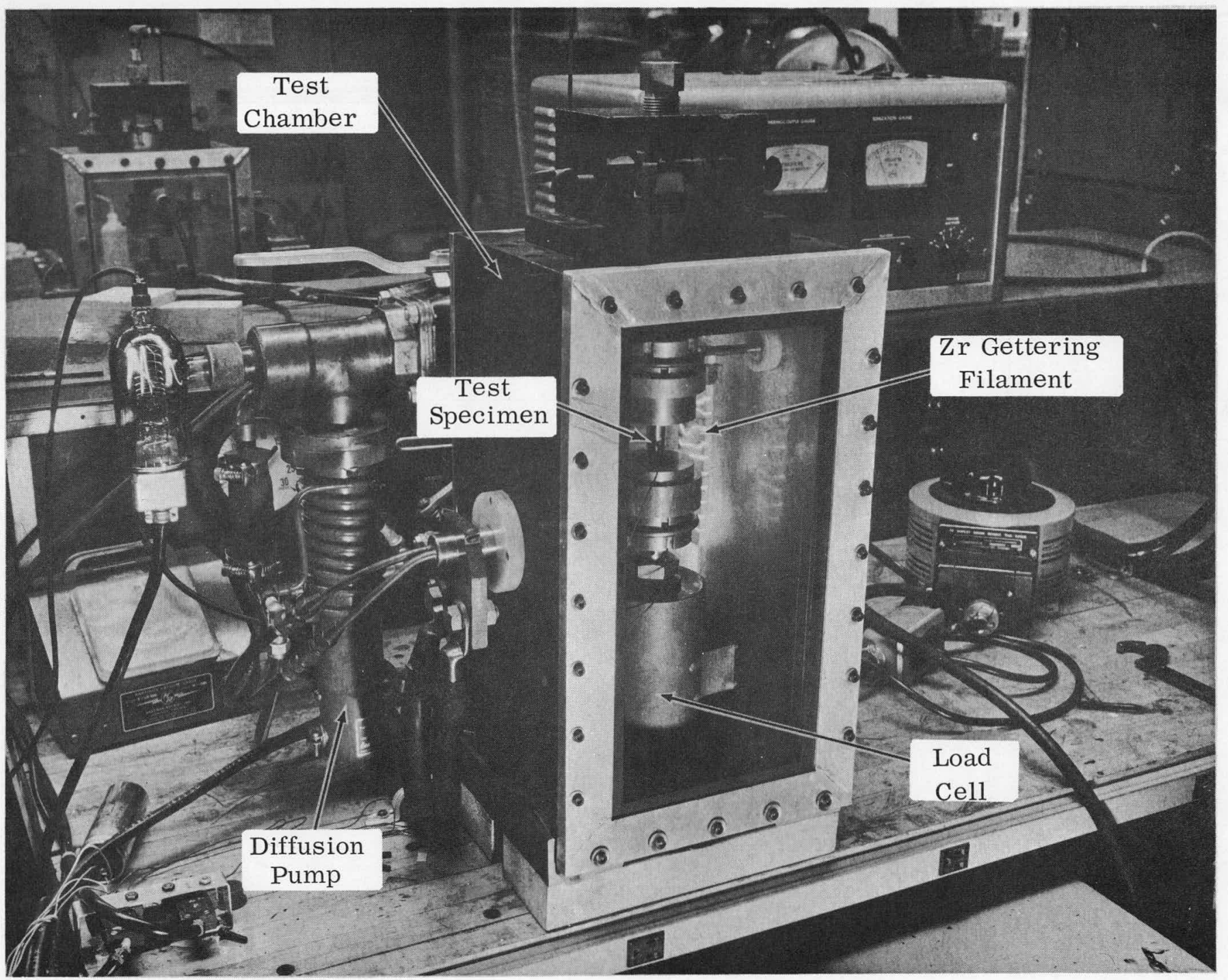

HIGH-VACUUM TSF SETUP

FIGURE 1 
NOTE: See List of Symbols, page 9, for definitions of terms.

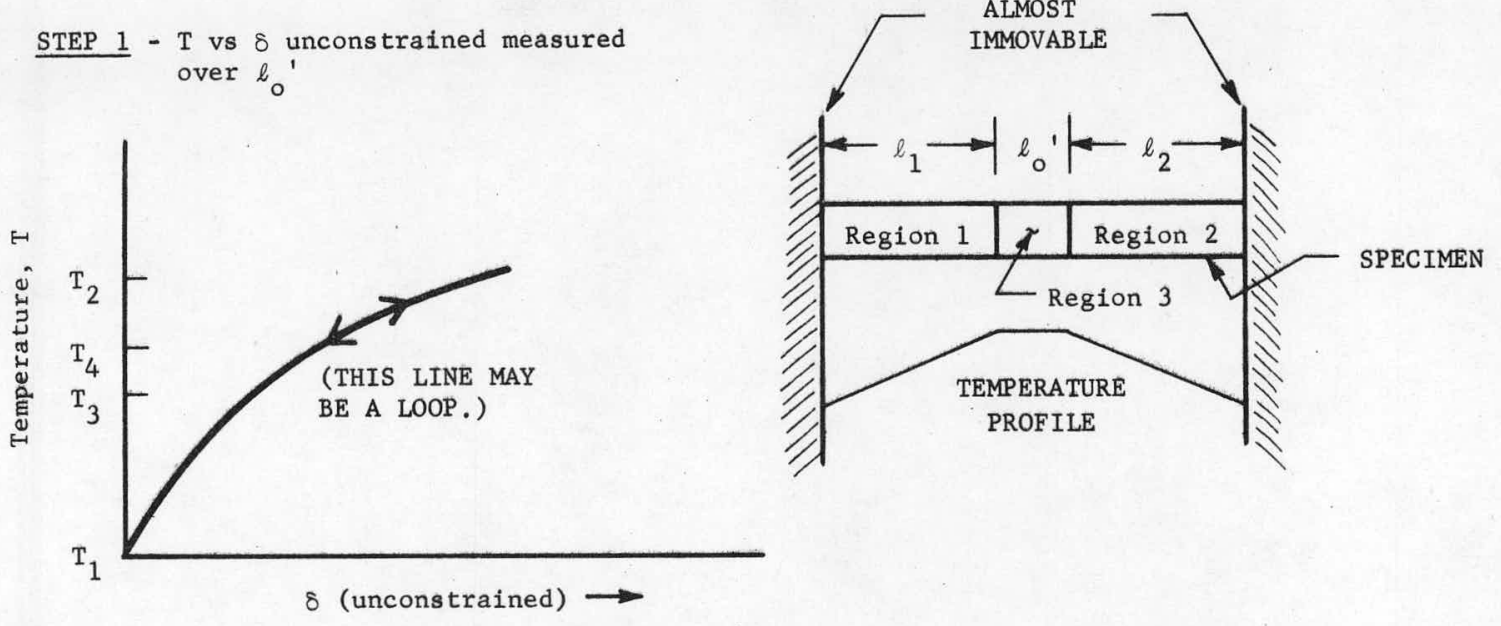

STEP 2 - P vs T, specimen constrained

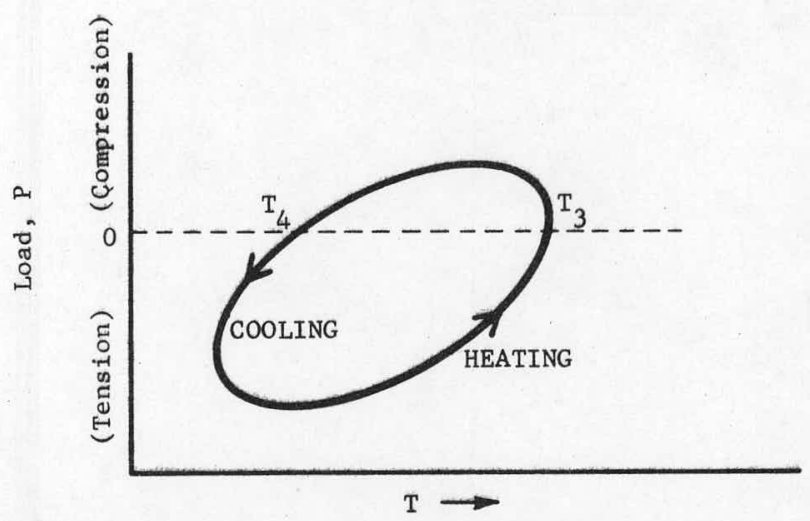

$$
\begin{aligned}
& \mathrm{T}_{4}-\mathrm{T}_{3} \propto \ell_{1} \Delta_{\epsilon_{\mathrm{p}_{1}}}+\ell_{2} \Delta_{\epsilon_{\mathrm{p}_{2}}}+\ell_{\mathrm{o}}^{\prime} \Delta_{\epsilon_{\mathrm{p}_{3}}}=\delta_{1} . \\
& \mathrm{T}_{4}>\mathrm{T}_{3} \text {. } \\
& \mathrm{T}_{4}-\mathrm{T}_{3}=\delta_{\mathrm{p}} \text {, neglecting the fact that the }
\end{aligned}
$$

STEP 3 - p Vs 8 constrained measured over $\ell_{0}{ }^{\prime}$

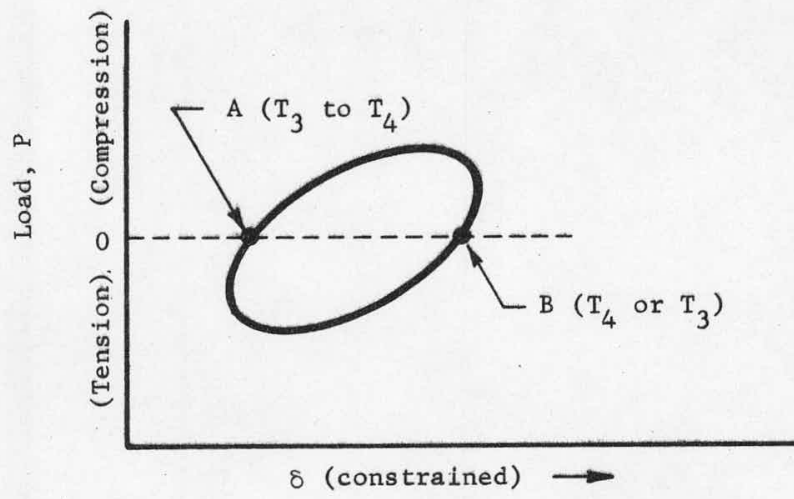

$\mathrm{A}-\mathrm{B} \propto_{\ell_{0}} \Delta_{\epsilon}^{\prime \prime}{ }_{\mathrm{p}_{3}}-\left(\ell_{1} \Delta_{\epsilon} \mathrm{p}_{1}+\ell_{2} \Delta_{\epsilon_{\mathrm{p}_{2}}}\right)=\delta_{2}$.

$A-B<0$ if $T_{3}$ is at point $A$.

$A-B>0$ if $T_{3}$ is at point $B$.

STEP 4

GRAPHICAL METHOD OF OBTAINING $\triangle \epsilon_{\mathrm{p}}$ MAXIMUM

$\Delta_{\epsilon_{3}}\left(\right.$ in $\left.\ell_{0}^{\prime}\right)=\frac{\delta_{1}+\delta_{2}}{\ell_{0}^{\prime}}$.

FIGURE 2 
NOTE: See List of Symbols, page 9, for definitions of terms.

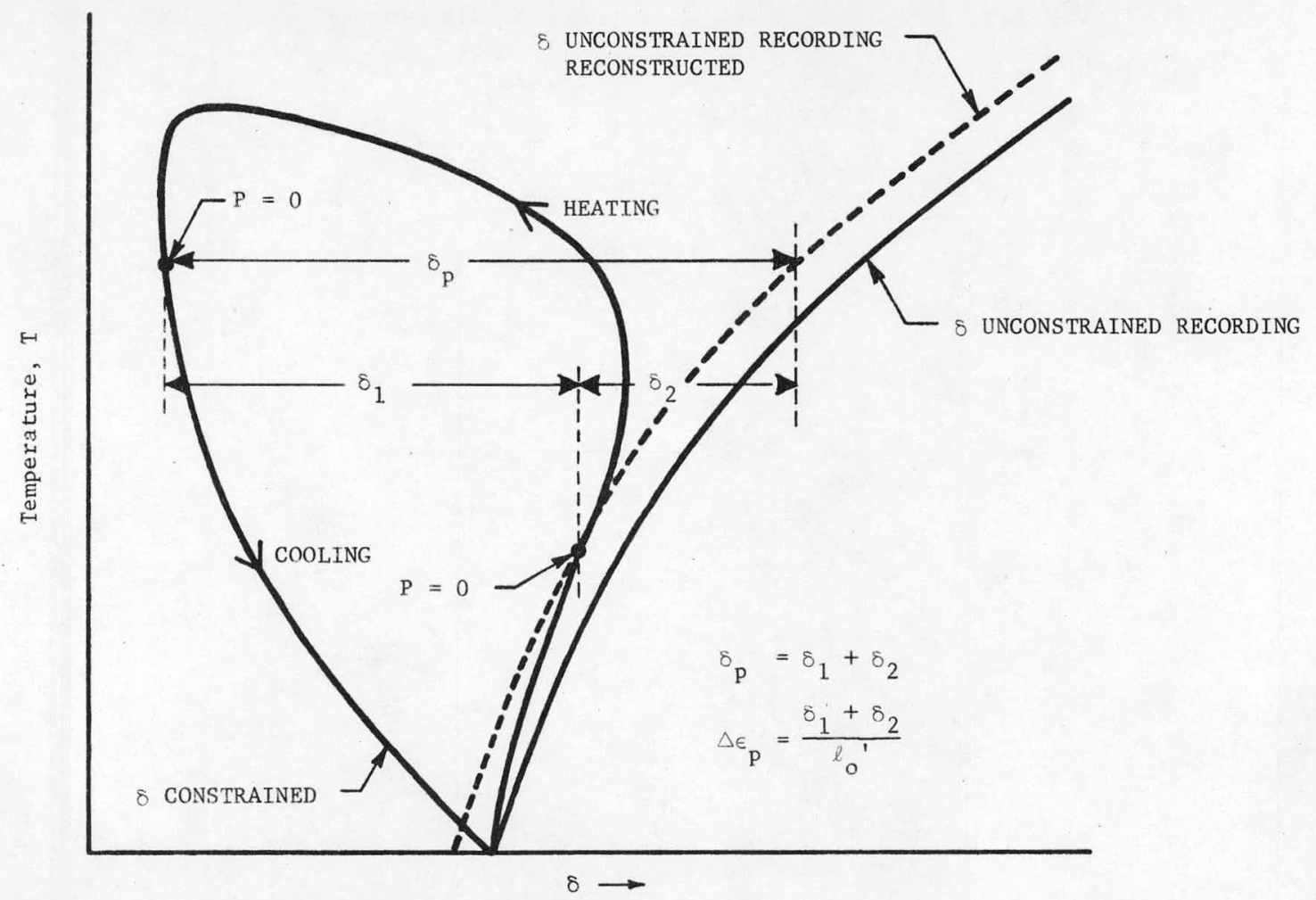

a. $b_{0}^{\prime}$ under more than $100 \%$ constraint

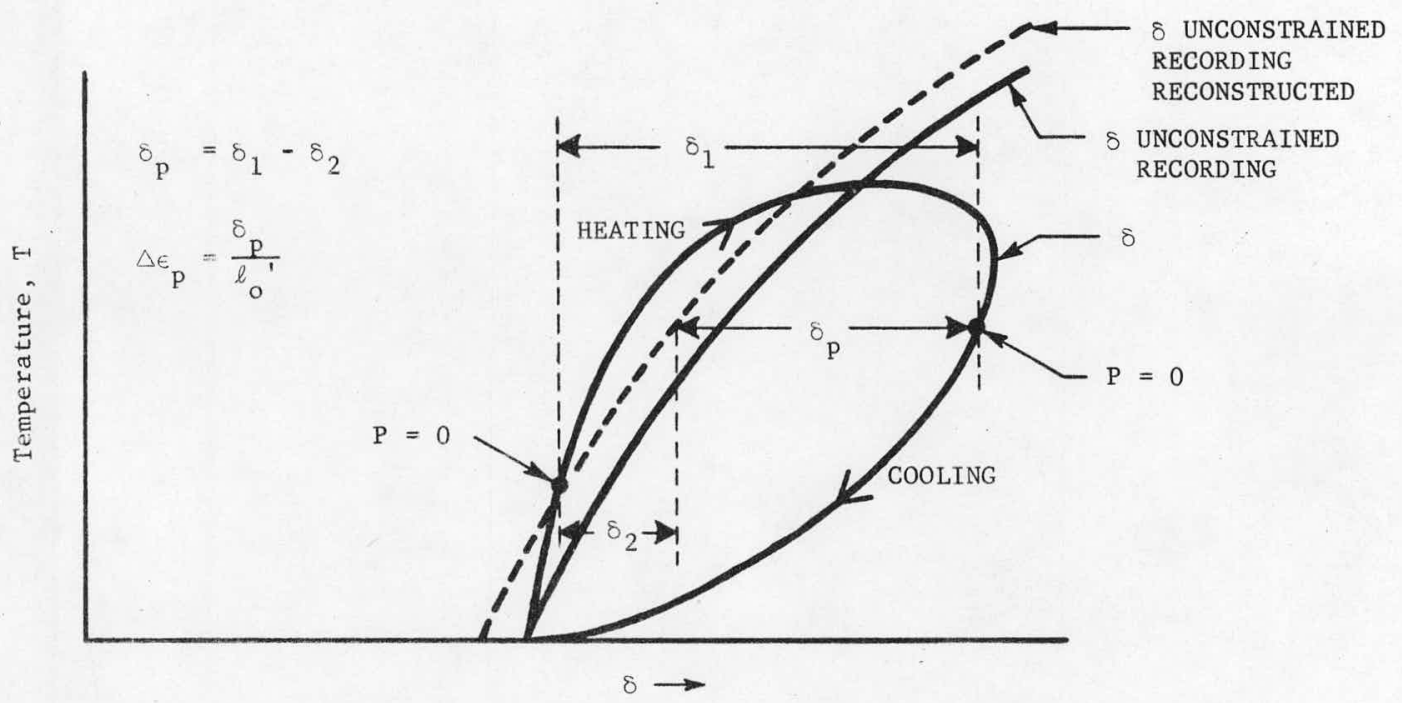

b. $\ell_{c}^{\prime}$ under less than $100 \%$ constraint

GRAPHICAL METHOD OF OBTAINING $\Delta \epsilon$ CURVES RECORDED DIRECTLY ON X-Y RECORDER

FIGURE 3 


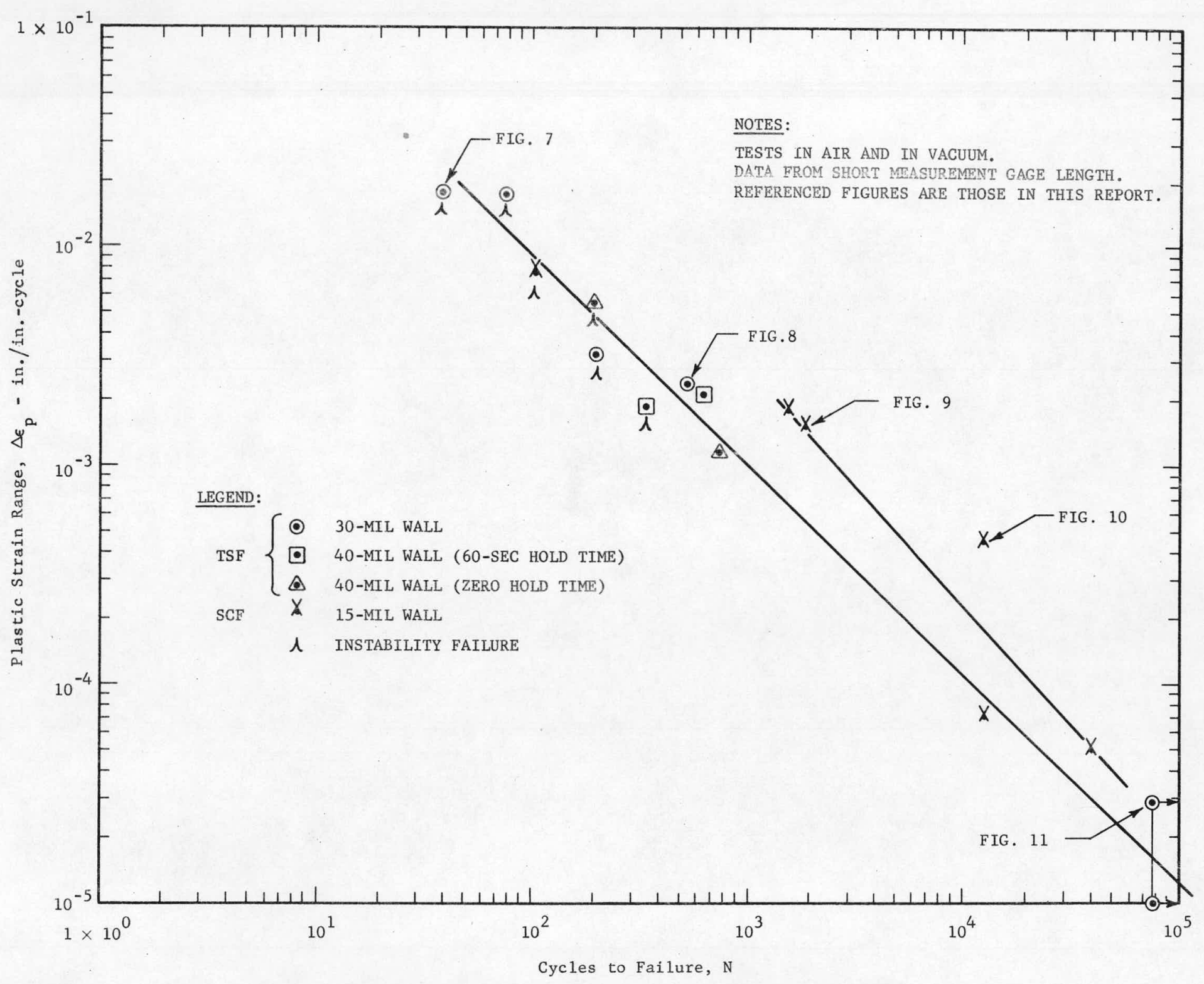

PLASTIC STRAIN RANGE VERSUS CYCLES TO FAILURE FOR A302B FERRITIC PRESSURE-VESSEL STEEL 


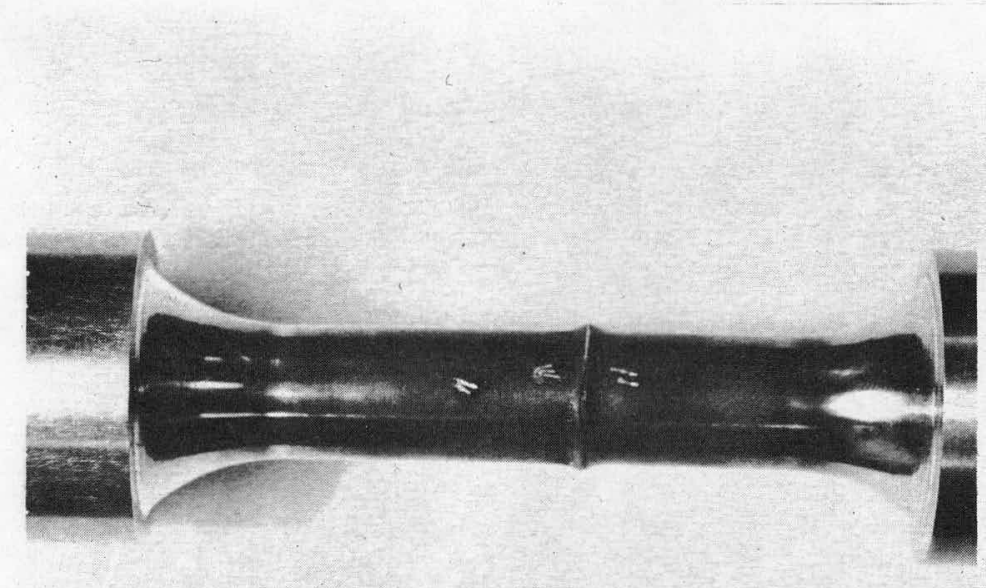

FAILED TSF SPECIMEN

ILLUSTRATING INSTABILITY-TYPE FAILURE

FIGURE 5 


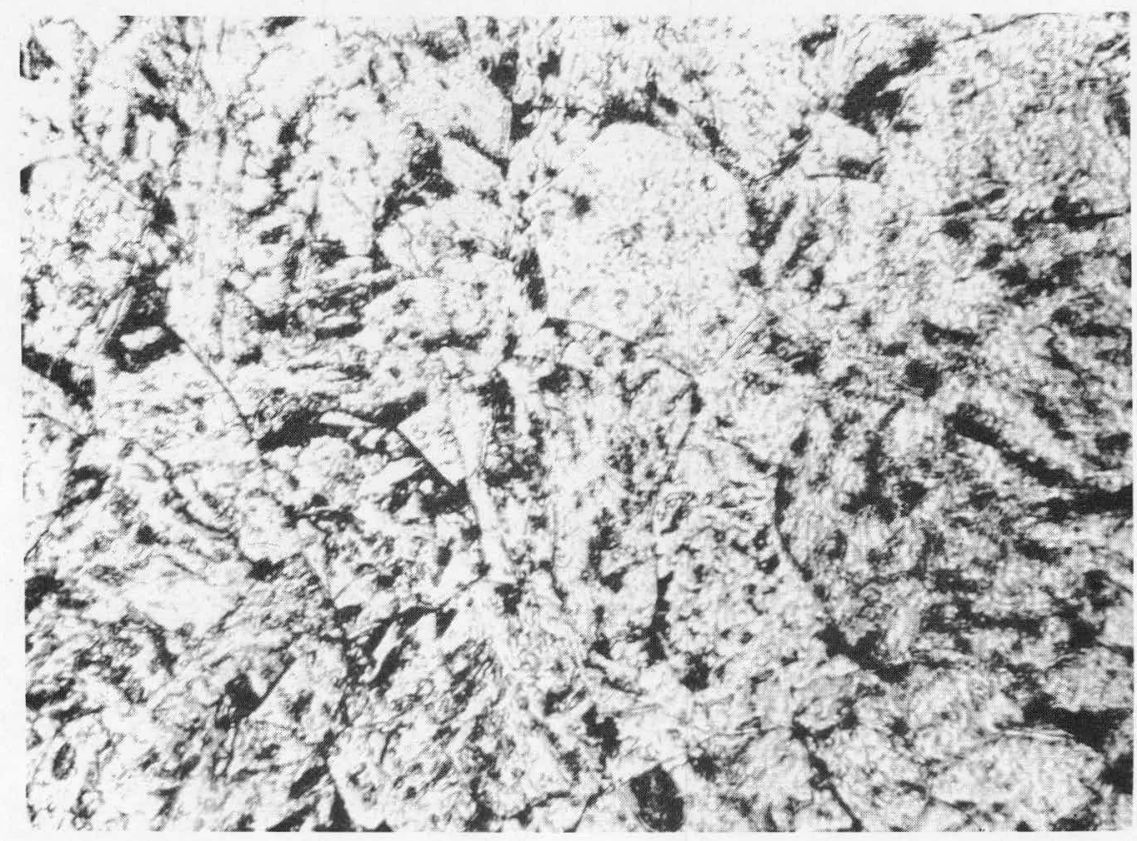

$750 \times$

Neg. \#5102

\section{AS-RECEIVED (ANNEALED) ASTM TYPE A302B FERRITIC PRESSURE-VESSEL STEEL}

Etched 15 sec in 5\% Nital. Hardness: Vickers $26 ; R_{H} 19$.

\section{FIGURE 6}

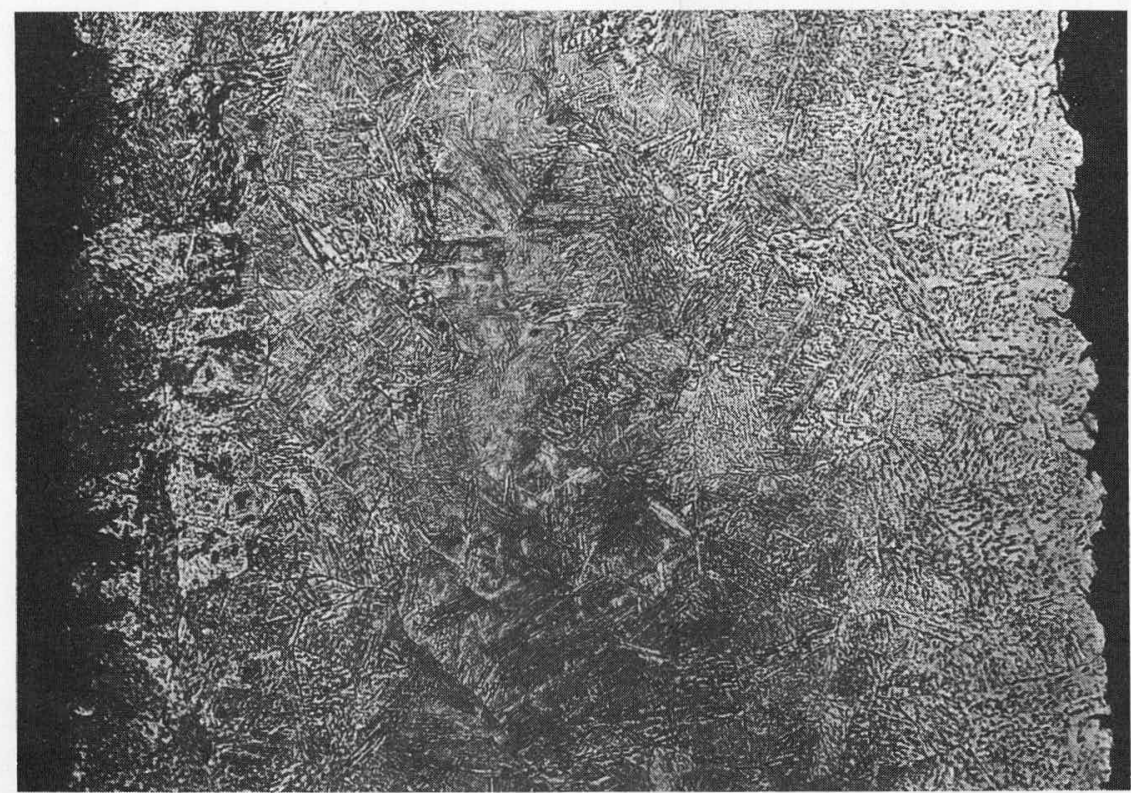

TSF-TESTED A302B FERRITIC PRESSURE-VESSEL STEEL Specimen 251. Test IV.A.1.a.2.c) $-2 c^{*}$

Etched $7 \mathrm{sec}$ in 5\% Nital. Hardness: Vickers 33.

FIGURE 7 


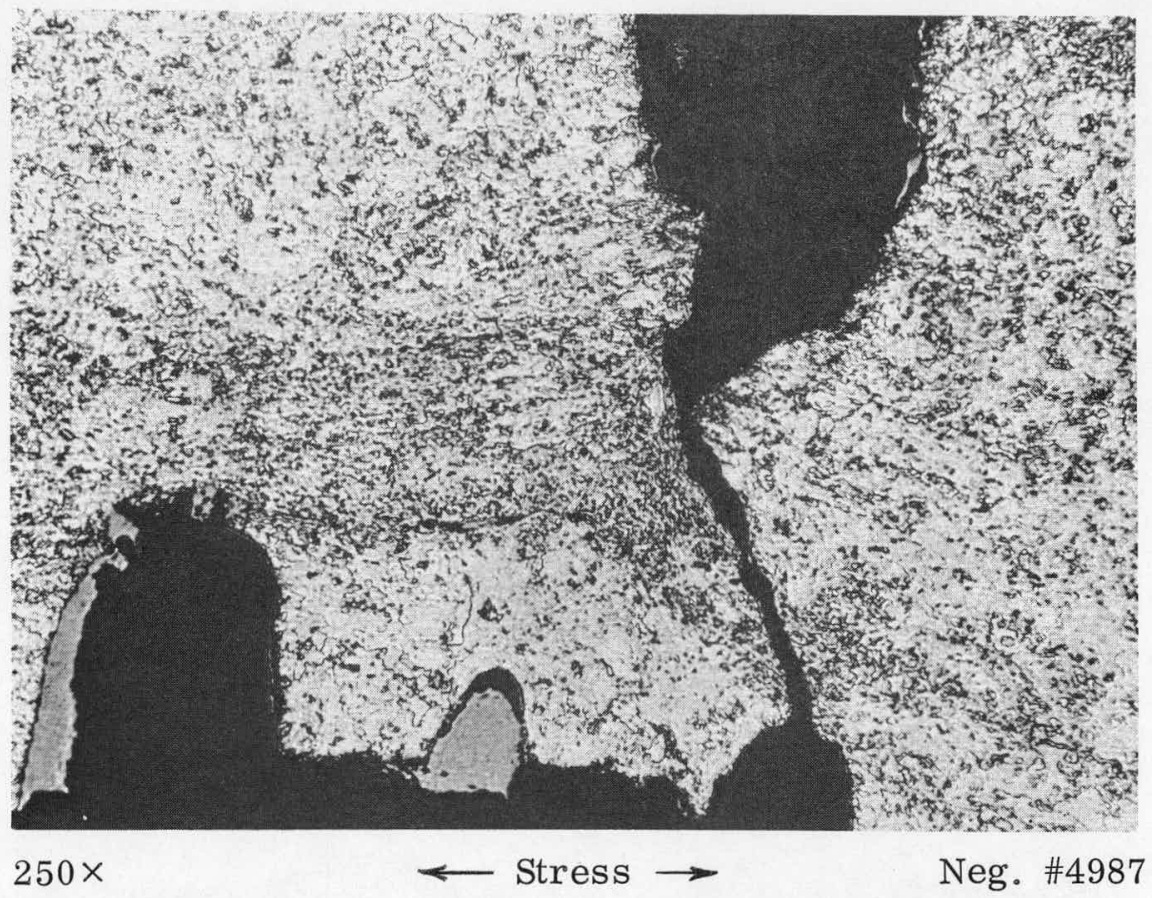

TSF-TESTED A302B FERRITIC PRESSURE-VESSEL STEEL Specimen 253. Test IV.A.1.a.2. a) -2 b Etched $80 \mathrm{sec}$ in $1 \%$ Nital.

FIGURE 8

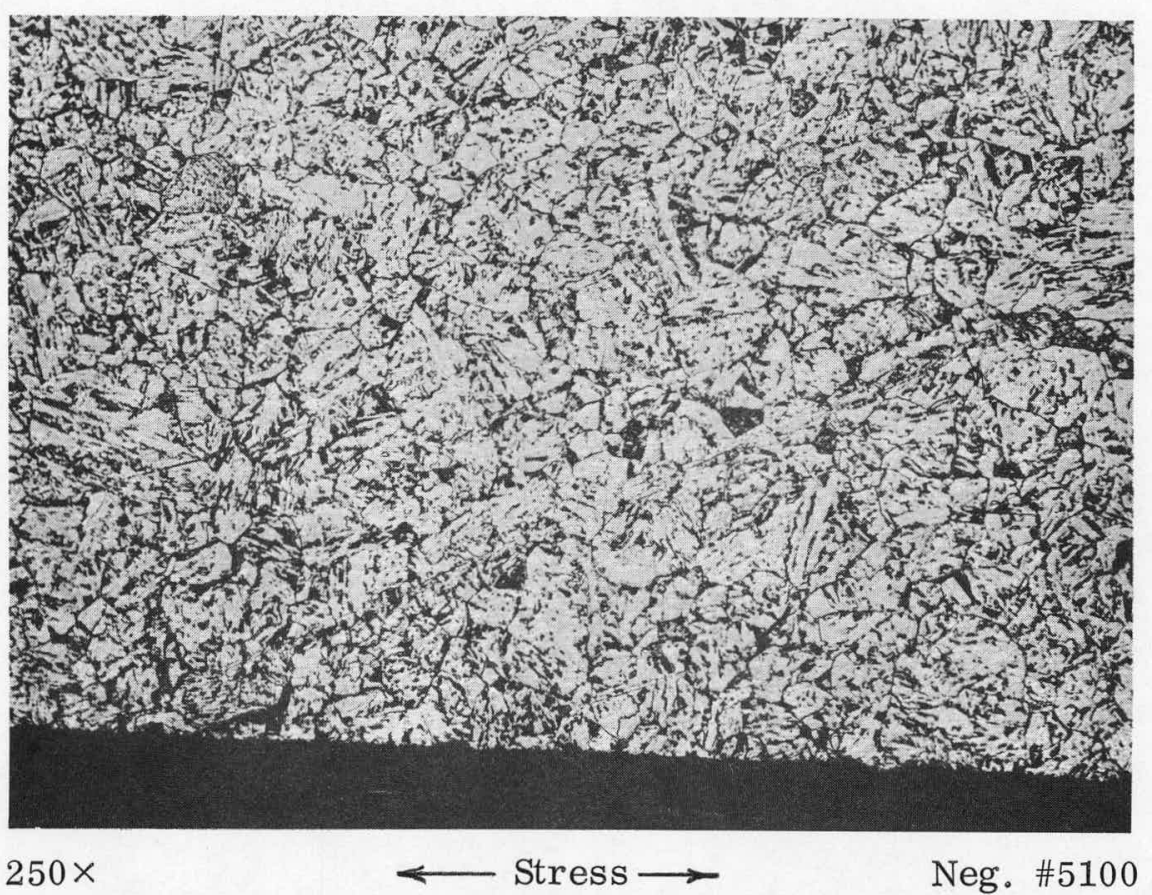

SCF-TESTED A302B FERRITIC PRESSURE-VESSEL STEEL Specimen 287. Test IV.A.1.a.1.e)-1b

Etched $15 \mathrm{sec}$ in $5 \%$ Nital. 


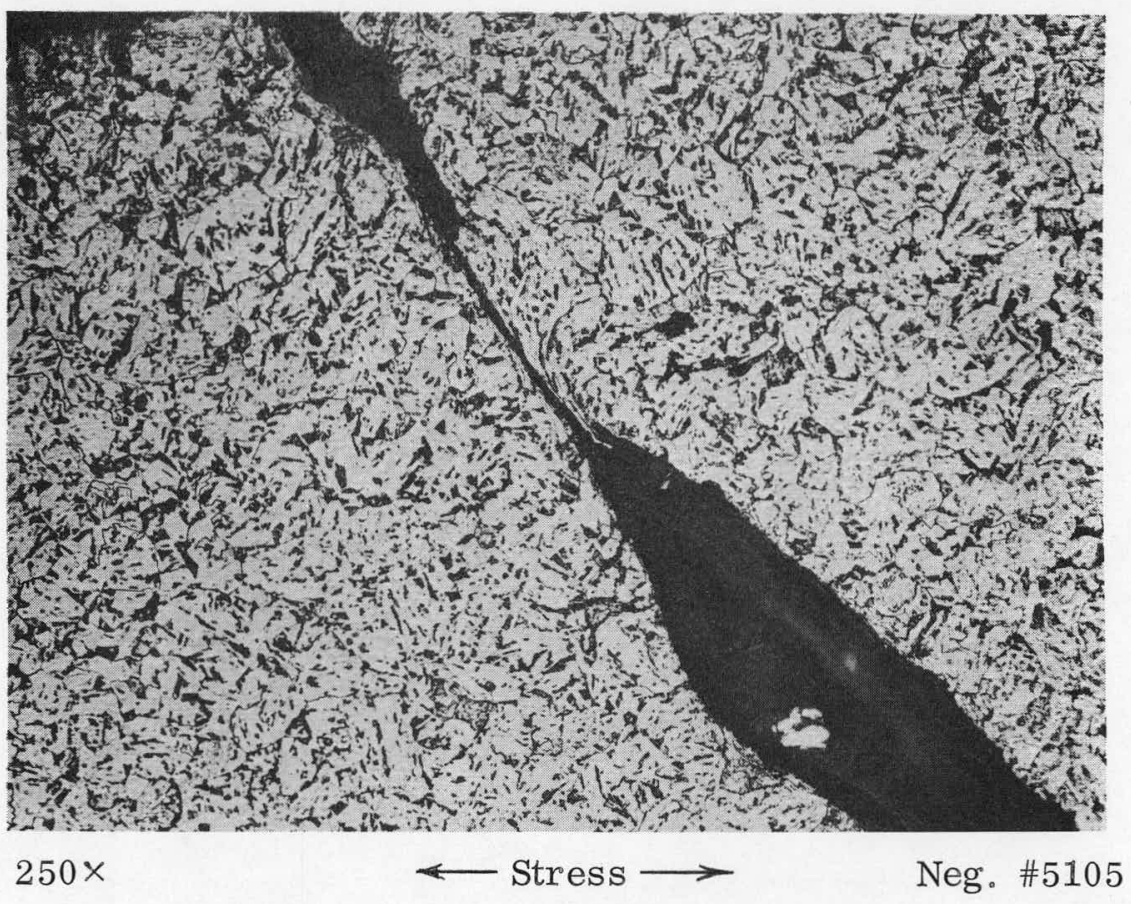

SCF-TESTED A302B FERRITIC PRESSURE-VESSEL STEEL Specimen 292. Test IV.A.1.a. 1.e)-xa (Test temp。 $=400^{\circ} \mathrm{C}$ ) Etched $10 \mathrm{sec}$ in $5 \%$ Nital.

FIGURE 10

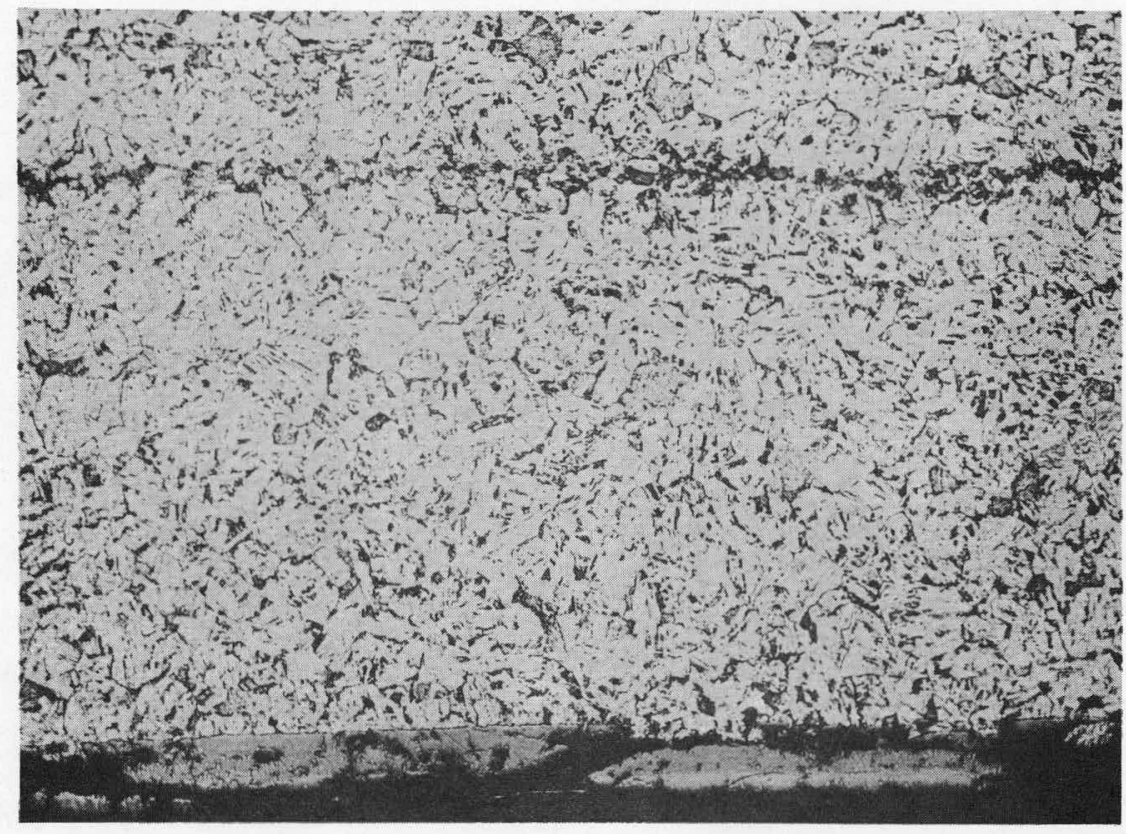

$250 \times$

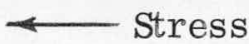

Neg。 \#5112

TSF-TESTED A302B FERRITIC PRESSURE-VESSEL STEEL Specimen 275. Test IV.A。1。a.2.c)-4c

Etched $5 \mathrm{sec}$ in $5 \%$ Nital。 


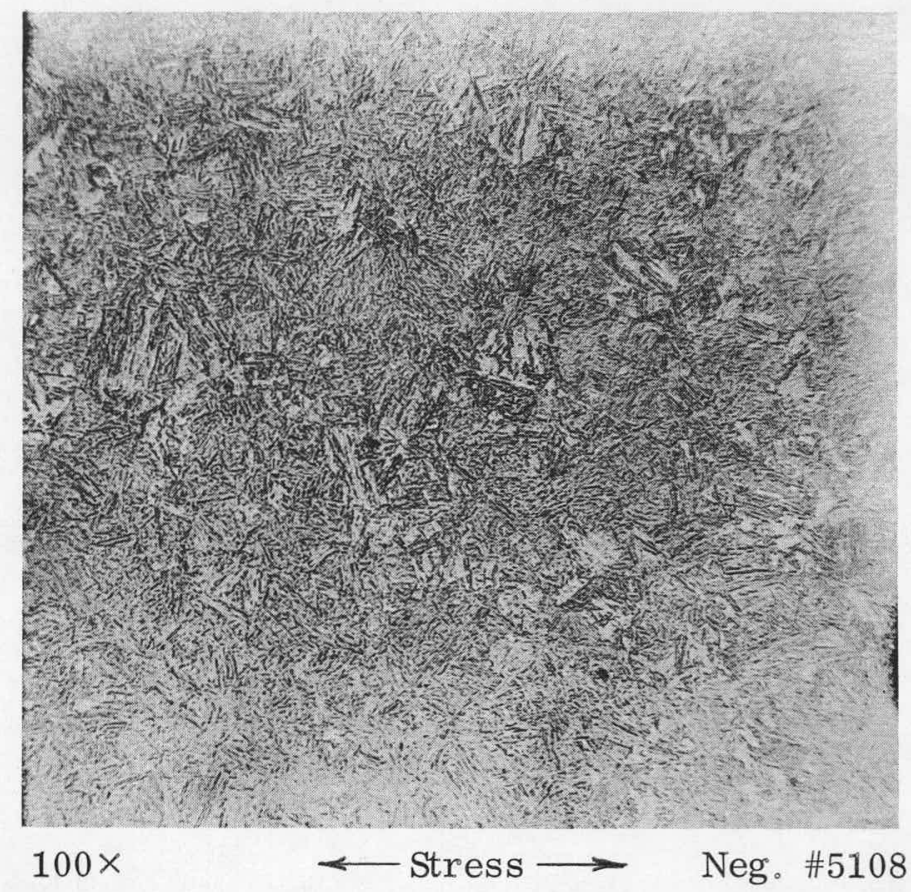

STRUCTURE OF A302B FERRITIC STEEL

WATER QUENCHED FROM $927^{\circ} \mathrm{C}\left(1700^{\circ} \mathrm{F}\right)$

Etched $7 \mathrm{sec}$ in $5 \%$ Nital. Hardness: Vickers 35.6

FIGURE 12

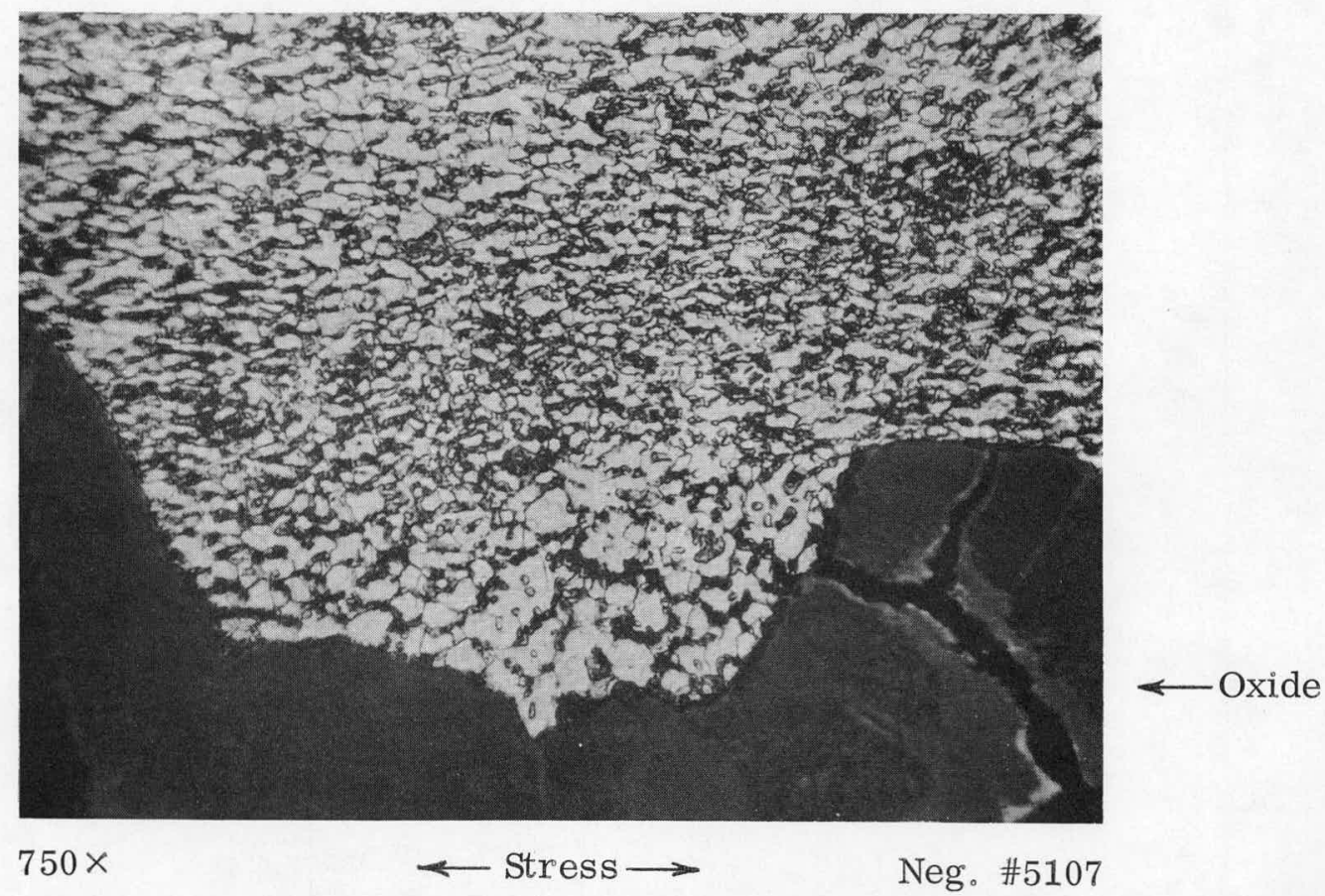

TSF-TESTED A302B FERRITIC PRESSURE-VESSEL STEEL Specimen 261。 Test IV.A.1.a.2. a)-2c

Etched $7 \mathrm{sec}$ in $5 \%$ Nital. 


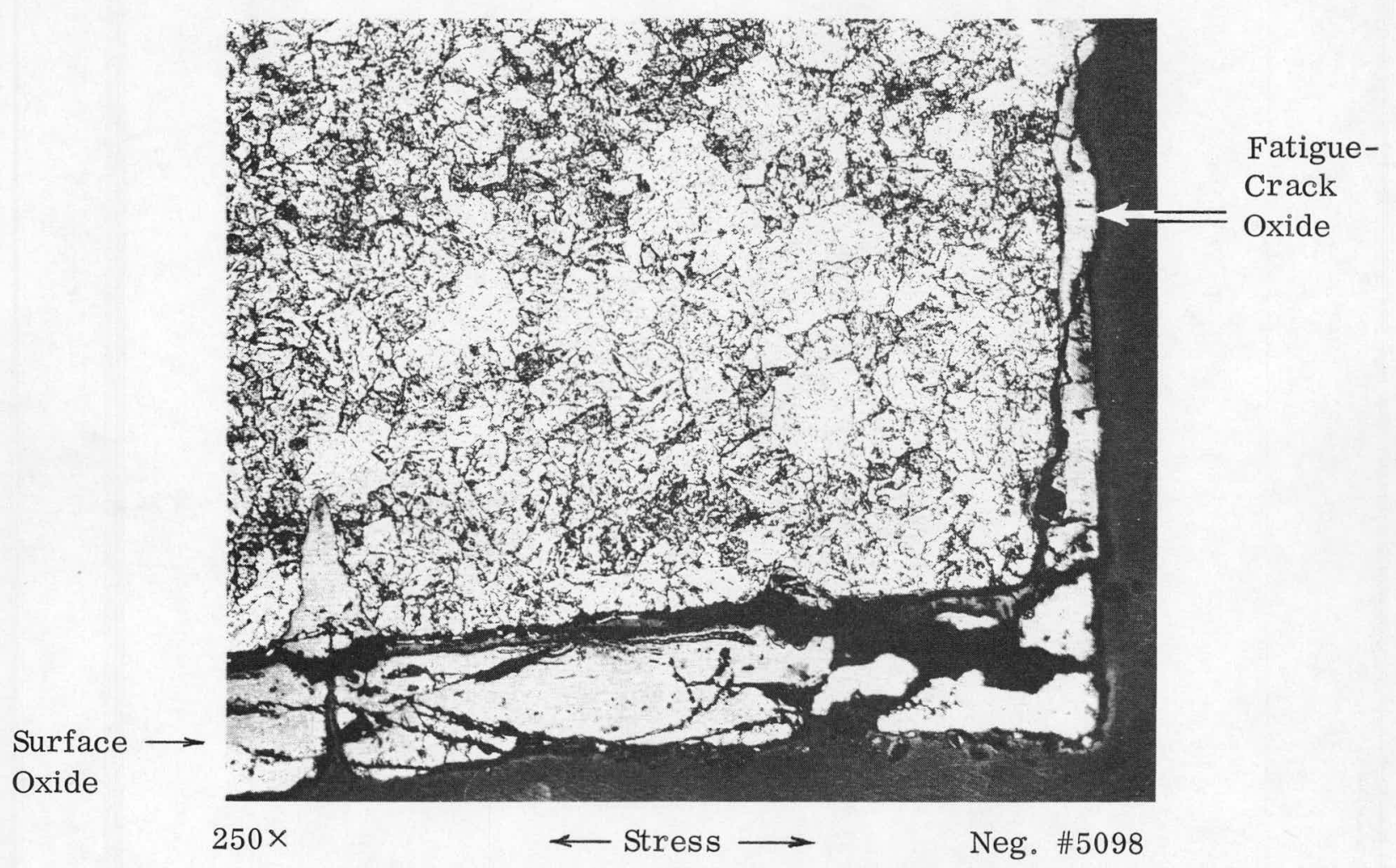

TSF-TESTED A302B FERRITIC PRESSURE-VESSEL STEEL SHOWING OXIDE FORIMATION IN FATIGUE CRACK Specimen 268. Test IV.A.1。a,3。c)-1c Etched $7 \mathrm{sec}$ in $5 \%$ Nital。

FIGURE 14 


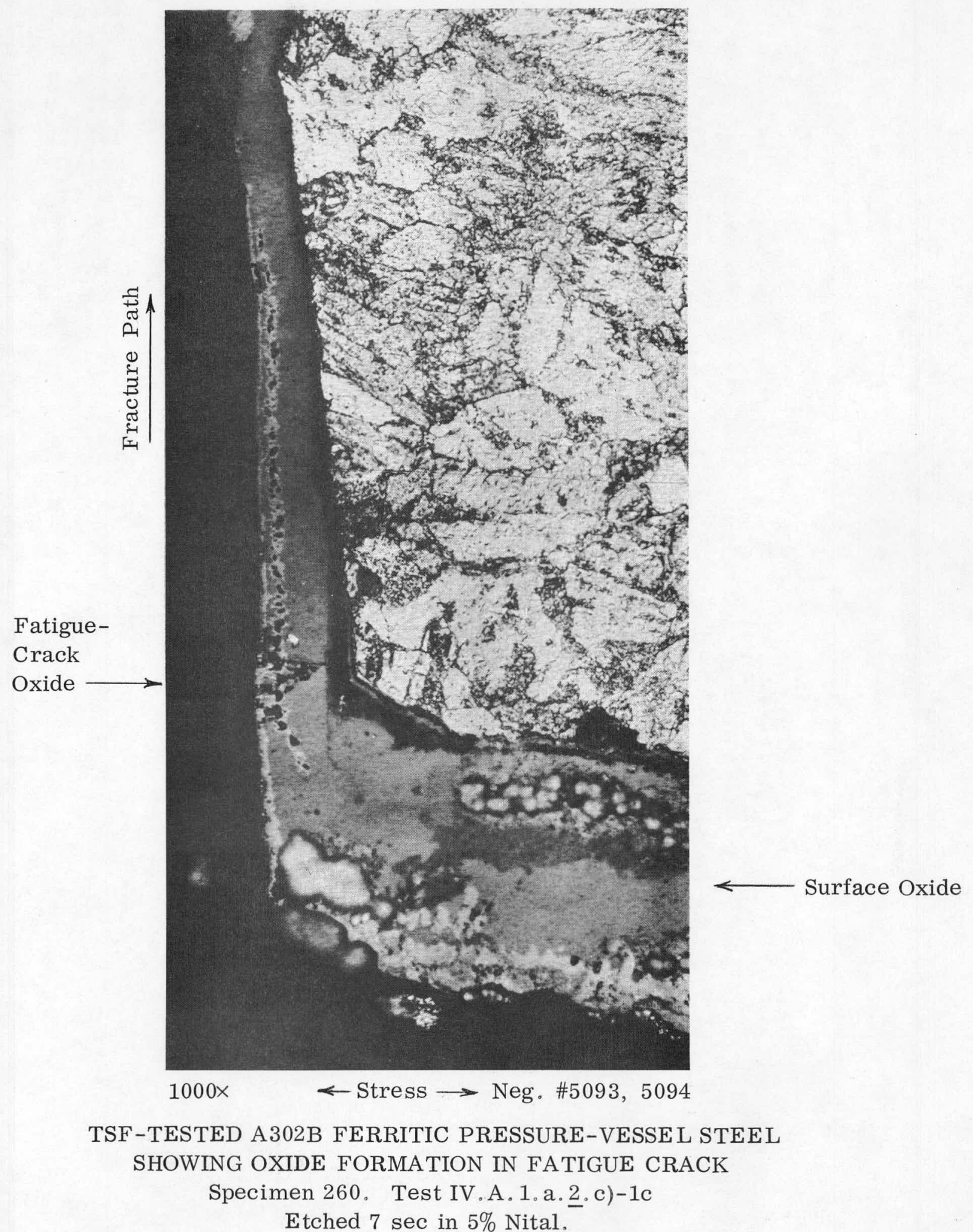

Etched $7 \mathrm{sec}$ in $5 \%$ Nital.

FIGURE 15 


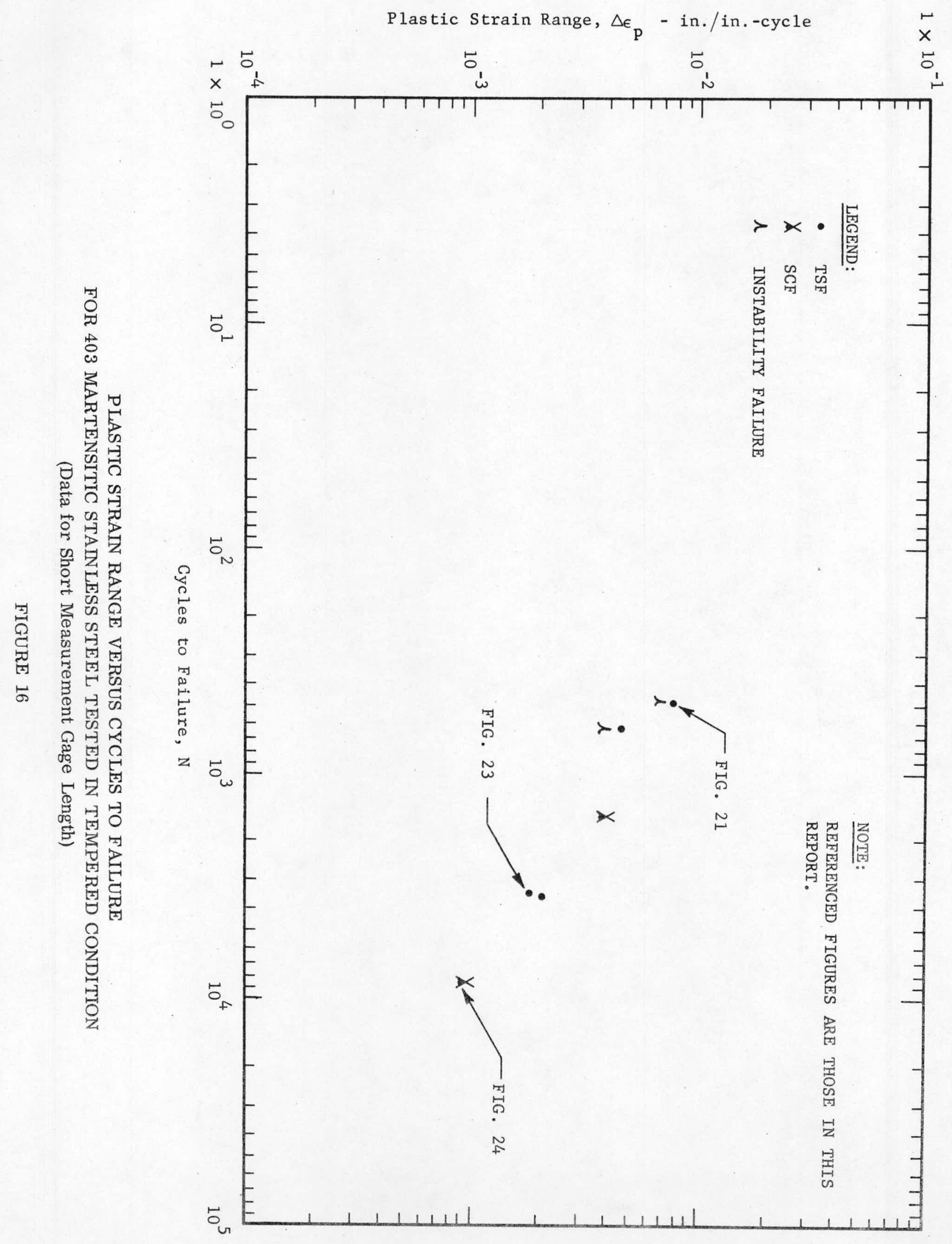




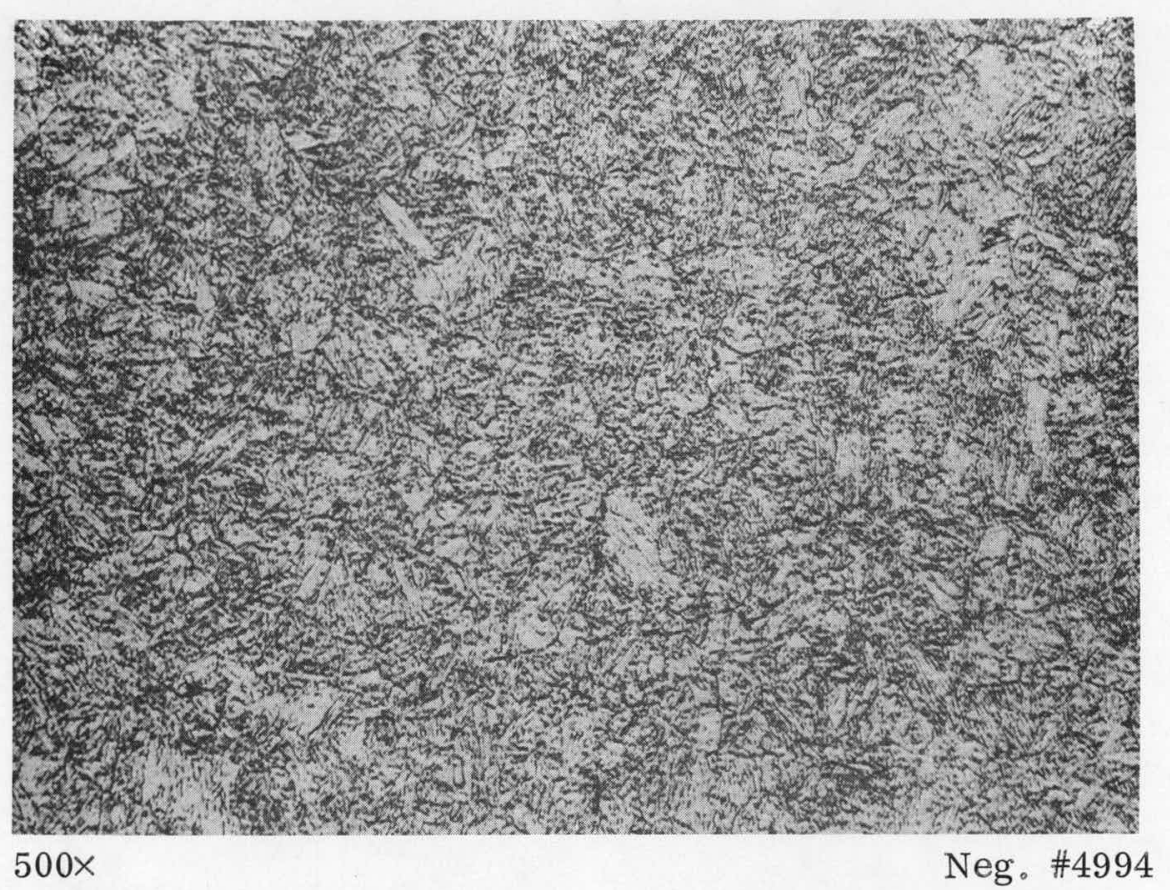

a. Electrolytic Etch: 10\% Oxalic Acid.

Hardness: $R_{B}$ 96-98

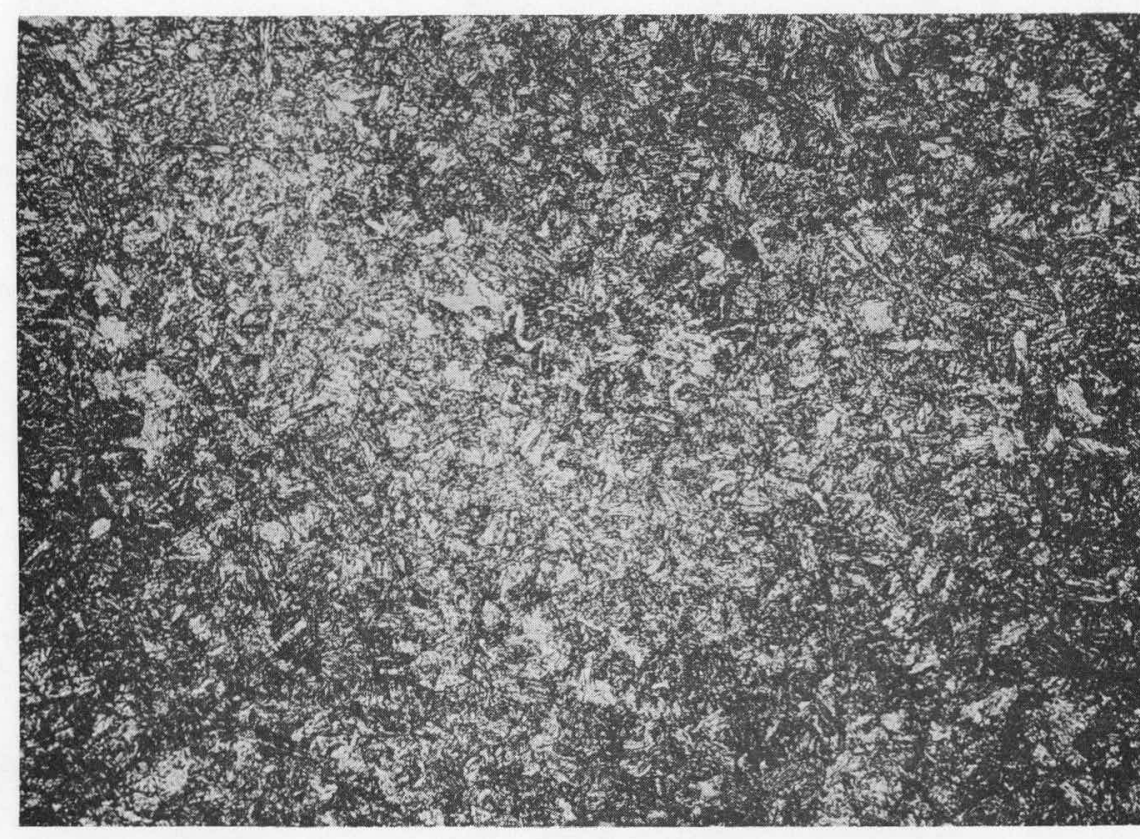

$250 \times$

Neg。 \#5113

b. $\quad$ Etched 7 seconds in Marbles Reagent

AS-RECEIVED (ANNEALED) TYPE 403 STAINLESS STEEL 


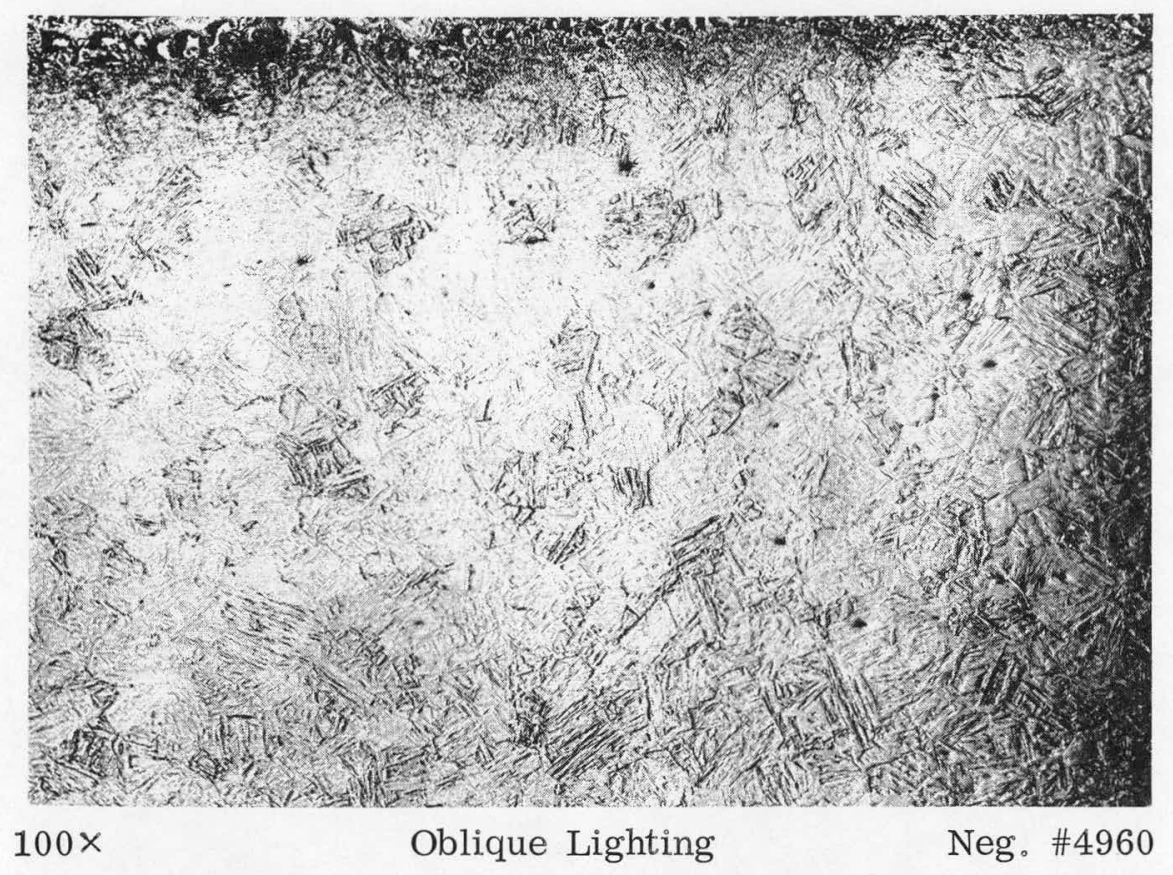

TYPE 403 STAINLESS STEEL QUENCHED IN HELIUM FROM $1000^{\circ} \mathrm{C}\left(1832^{\circ} \mathrm{F}\right)$

Etched in $10-\mathrm{HCl}, 3 \mathrm{HNO}_{3}, 100 \mathrm{CH}_{3} \mathrm{OH}$. Hardness: $\mathrm{R}_{\mathrm{C}} 42-44$ 。

FIGURE 18 


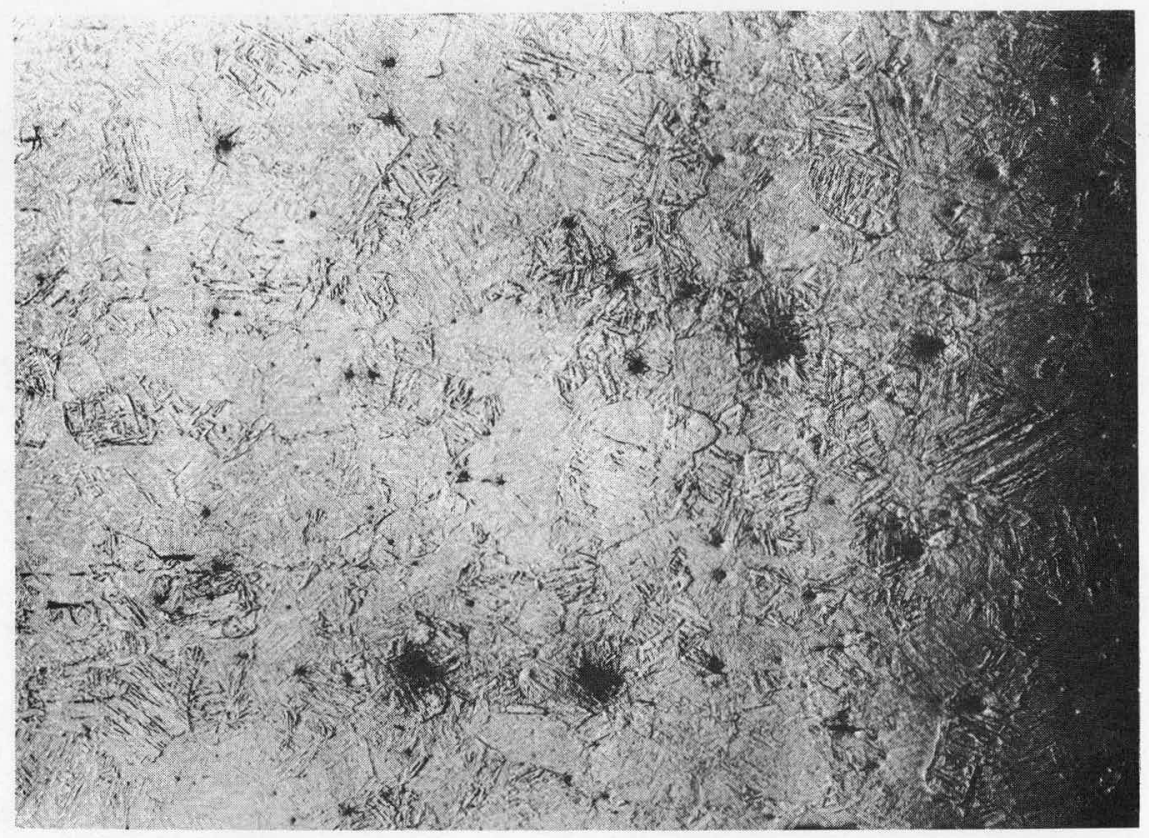

$100 \times$

Oblique Lighting

Neg. \#4961

TYPE 403 STAINLESS STEEL QUENCHED IN HELIUM AND TEMPERED 2 HOURS IN VACUUM AT $649^{\circ} \mathrm{C}\left(1200^{\circ} \mathrm{F}\right)$

Etched in $10-\mathrm{HCl}, 3-\mathrm{HNO}_{3}, 100-\mathrm{CH}_{3} \mathrm{OH}_{\text {。 Hardness: } \mathrm{R}_{\mathrm{C}}} 20-23$ FIGURE 19

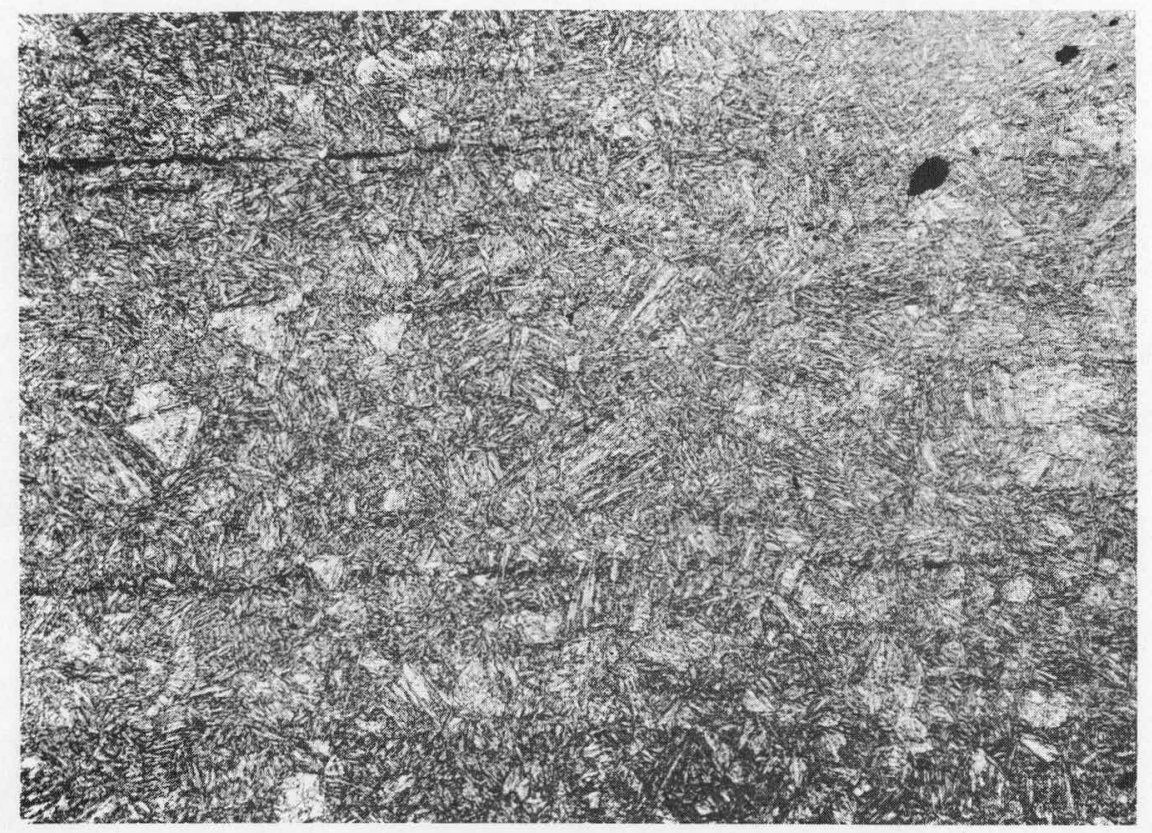

$100 \times$

Oblique Lighting

Neg。 \#4993

TYPE 403 STAINLESS STEEL, SAME HEAT TREATMENT AS IN FIGURE 19, PLUS 22 ADDITIONAL HOURS AT $649^{\circ} \mathrm{C}$ Same etch as in Figure 19. Hardness: $R_{B}$ 87-92 


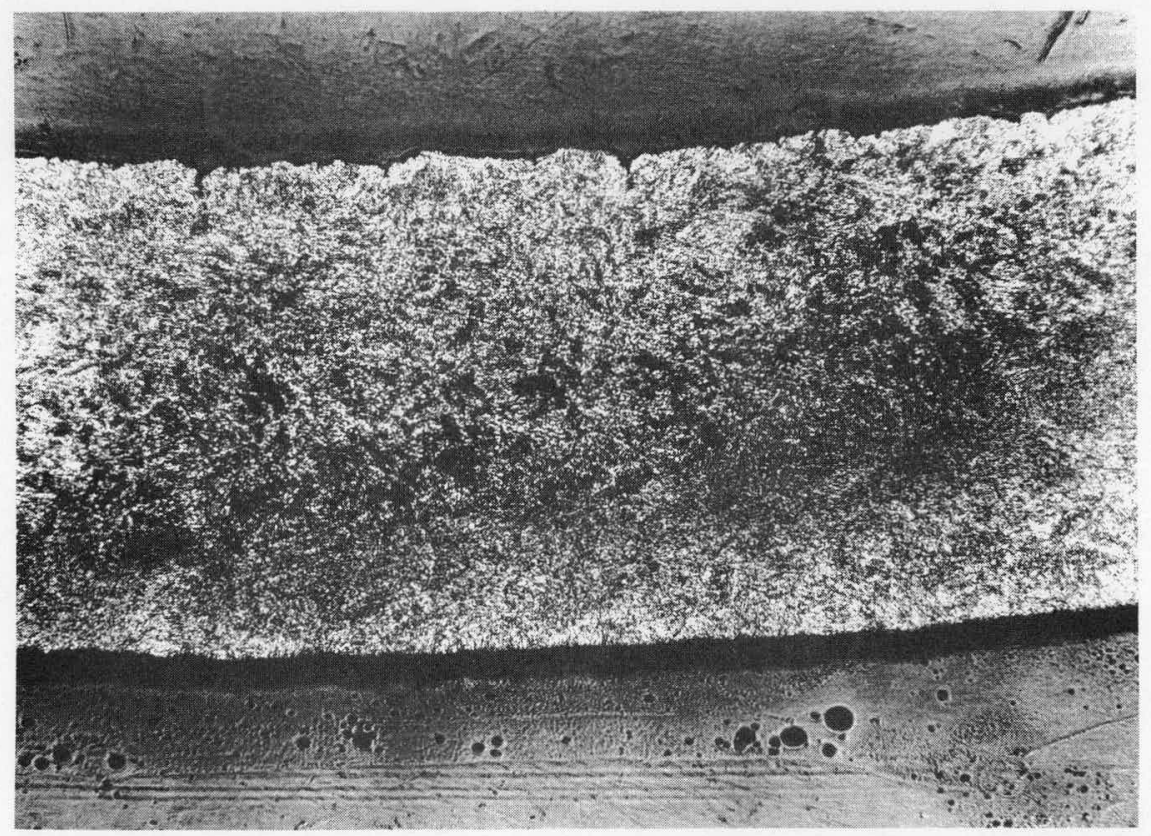

$100 \times$

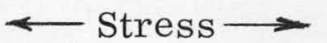

Neg. \#5110

TSF-TESTED 403 STAIN LESS STEEL

Specimen 353. Test III.A.4.a.1. c)-1d

Etched $5 \mathrm{sec}$ in Marbles Reagent. 1-min hold time at $\mathrm{T}_{\max }=700^{\circ} \mathrm{C}$

FIGURE 21

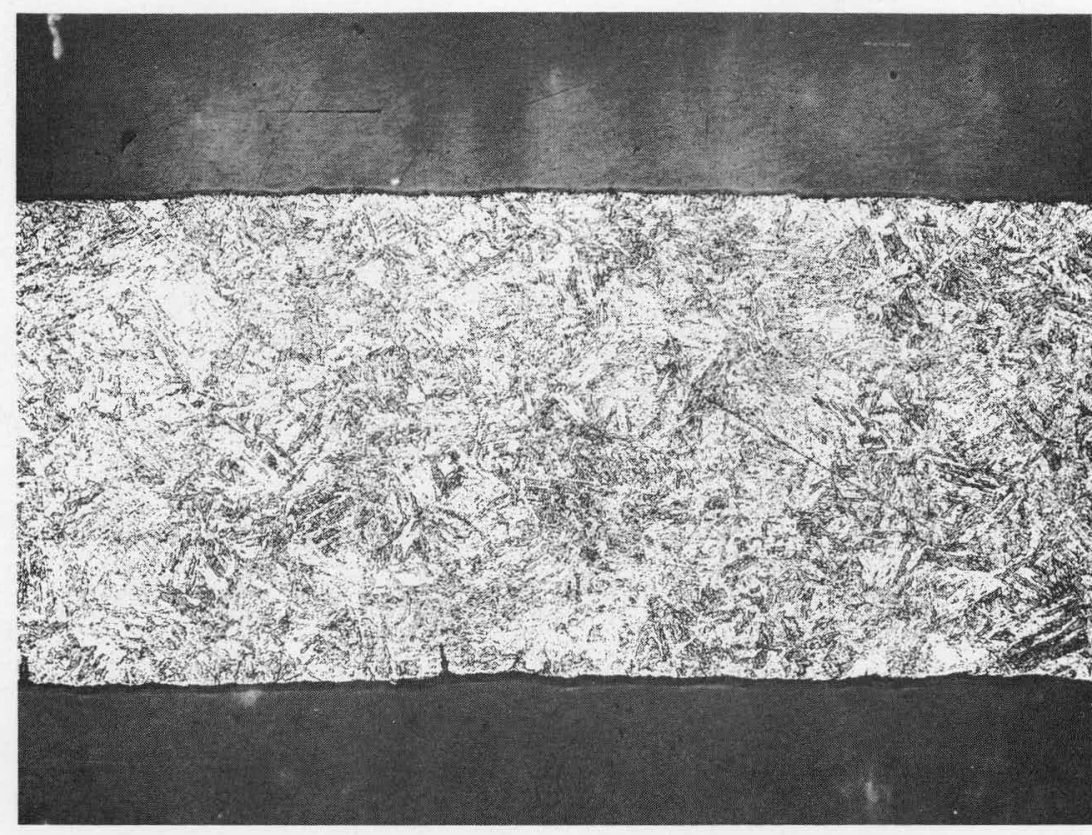

$100 \times$

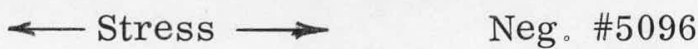

TSF-TESTED 403 STAINLESS STEEL

Specimen 365. Test III.A.4.a.1.a)-2b

Etched 5 sec on Marbles Reagent. Zero hold time at $\mathrm{T}_{\max }=700^{\circ} \mathrm{C}$ 


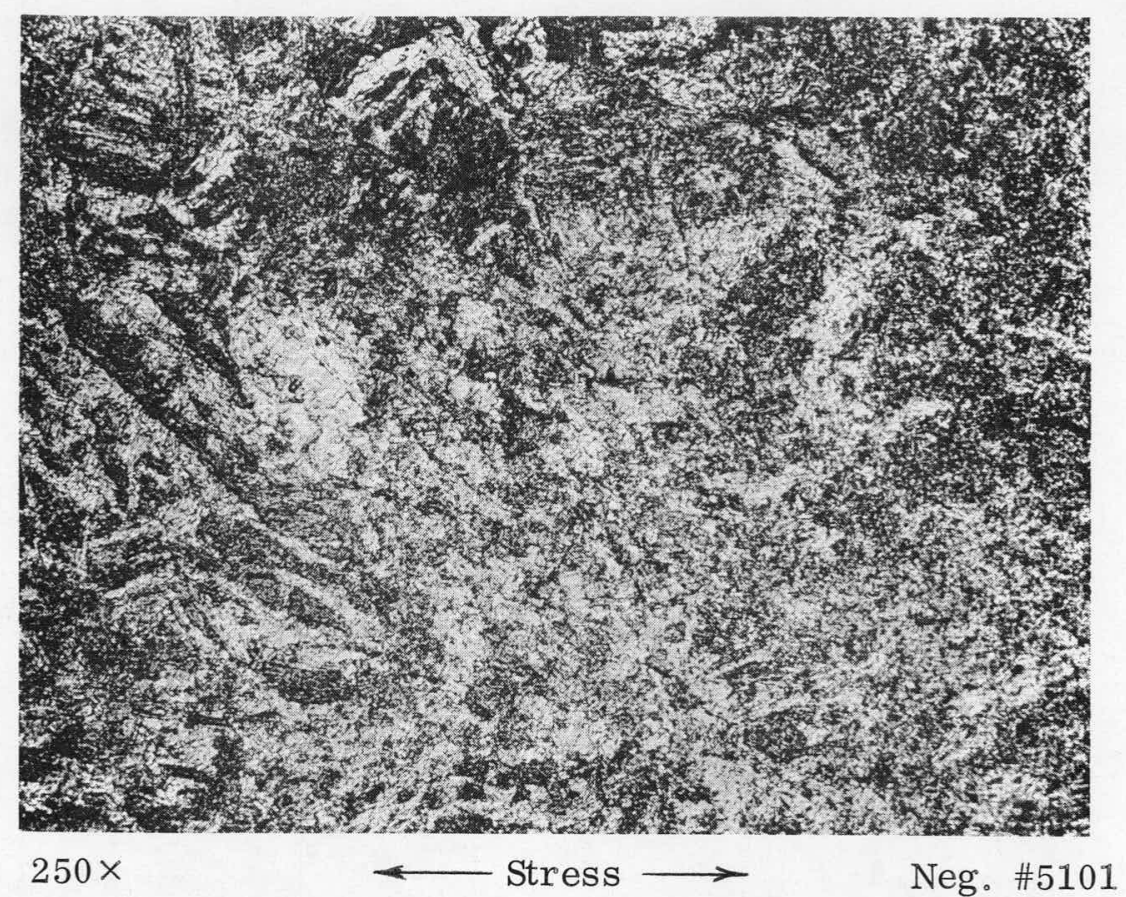

TSF-TESTED 403 STAINLESS STEEL

Specimen 356. Test III.A.4。a。1.c) - $1 \mathrm{c}\left(\mathrm{T}_{\max }=600^{\circ} \mathrm{C}\right)$ Etched $10 \mathrm{sec}$ in Marbles Reagent.

FIGURE 23

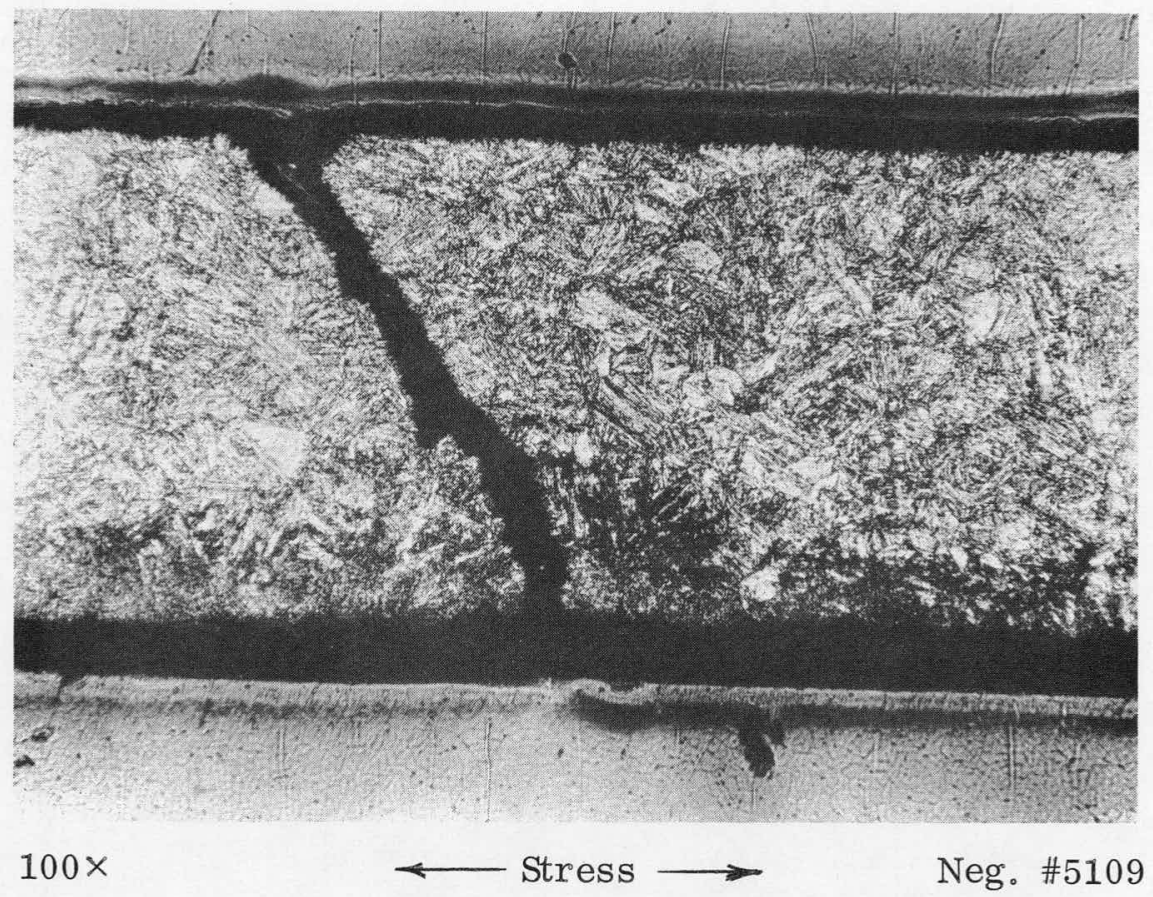

SCF-TESTED 403 STAINLESS STEEL

Specimen 354. Test III.A.4。a。1。e)-1e (Test temp。 $=400^{\circ} \mathrm{C}$ ) Etched $5 \mathrm{sec}$ in Marbles Reagent. 


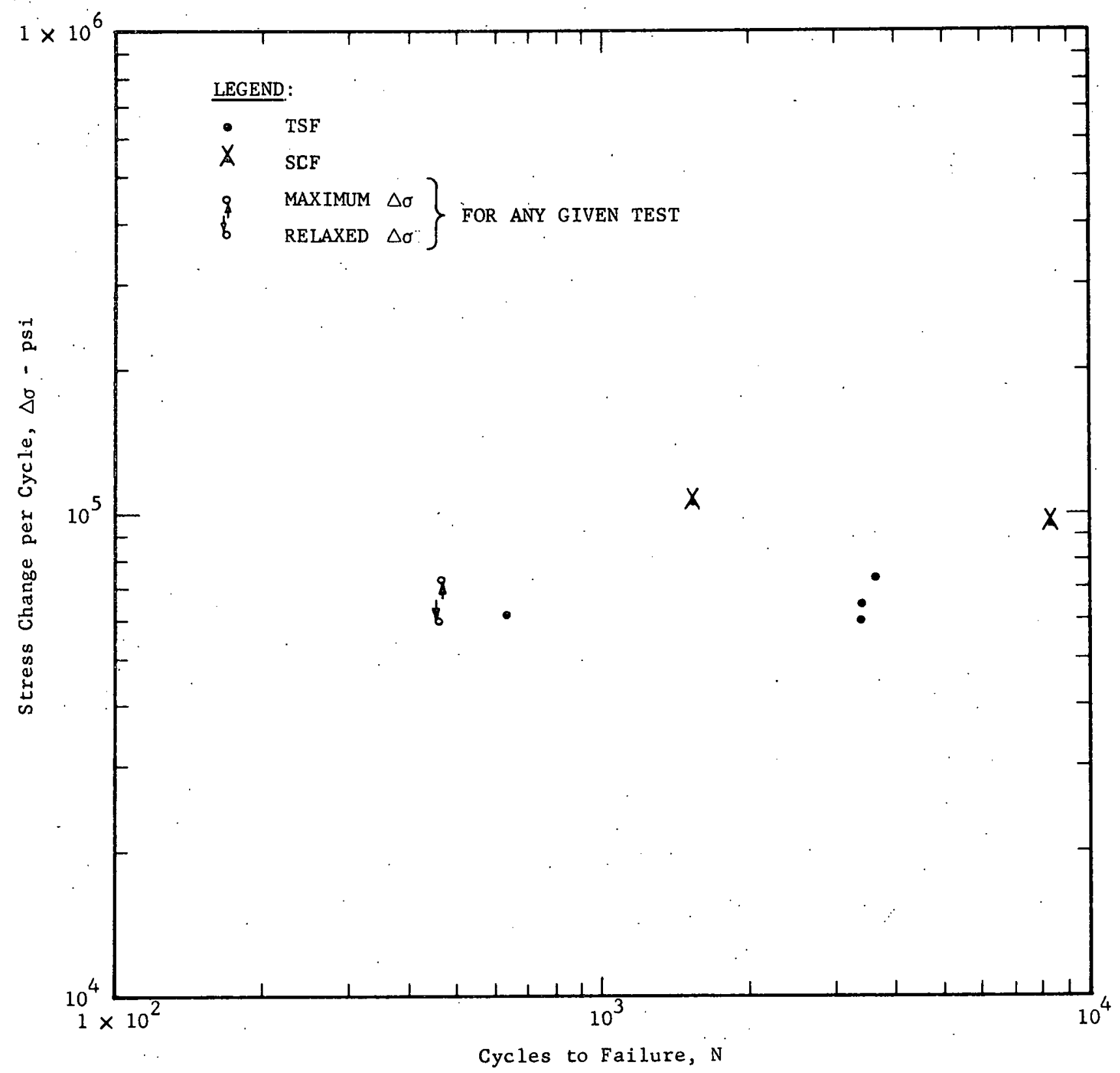

STRESS CHANGE ( TENSION PLUS COMPRESSION) PER CYCLE VERSUS CYCLES TO FAILURE FOR 403 STAINLESS STEEL

FIGÜRE 25 
USAEC

San Francisco Operations Office

2111 Bancroft Way

Berkeley 4, California

ATTN: W. H. Brummett, Jr.

USAEC

Division of Reactor Development

Washington 25, D. C.

ATTN: Office of Foreign Activities

Fuels \& Materials Development Branch

Nuclear Technology

Reports and Statistics Branch

Water Reactors Branch

Civilian Reactors

Water Systems Project Branch

Army Reactors

Argonne National Laboratory

9700 South Cass Avenue

Argonne, Illinois

Knolls Atomic Power Laboratory

P.O. Box 1072

Schenectady, New. York

Naval Research Laboratory

Washington 25, D.C.

ATTN: W. Pellini

Oak Ridge National Laboratory

P.O. Box P

Oak Ridge, Tennessee

ATTN: J: Weir

Metals and Ceramics Division 1

Professor JoDean Morrow

Department of Theoretical Applied Mechanics

University of Illinois 
Professor Harry Majors, Jr., Head

Mechanical Engineering Department

Seattle University

Seattle, Washington

Commander,

Aeronautical Systems Division

Directorate of Materials and Processes

Materials Central

Wright-Patterson Air Force Base, Ohio

ATTN: D. Forney

Combustion Engineering, Inc.

Nuclear Division

Prospect Hill Road

Windsor, Connecticut

ATTN: W. Chernok

General Electric Company

Atomic Power Equipment Department

P.O. Box 254

2151 South First Street

San Jose, California

ATTN: T. Pashos

Professor A. E. Carden

University of Alabama

Department of Engineering Mechanics

University, Alabama

United Nuclear Corporation

Development Division

5 New Street

White Plains, New York

ATTN: A. Strasser

ATL Files 


\section{ATTACHMENT A}

To expedite dissemination of technical information to those persons requiring it, this report has been issued without the administrative review necessary to protect the interest of the U. S. Government, the European Atomic Energy Community (Euratom) and the Contractor. The recipient of this report agrees that it is passed on to him in confidence, that he will maintain that confidence and make no disclosures or publication of the contents. 